Article

\title{
Control of Solvent-Based Post-Combustion Carbon Capture Process with Optimal Operation Conditions
}

\author{
Yih-Hang Chen, Ming-Tien Shen, Hsuan Chang * and Chii-Dong Ho
}

Department of Chemical and Materials Engineering, Tamkang University, Tamsui 25137, Taiwan; yihhang@mail.tku.edu.tw (Y.-H.C.); 401400618@s01.tku.edu.tw (M.-T.S.); cdho@mail.tku.edu.tw (C.-D.H.)

* Correspondence: nhchang@mail.tku.edu.tw; Tel.: +88-62-2623-2094

Received: 10 May 2019; Accepted: 5 June 2019; Published: 12 June 2019

\begin{abstract}
Solvent-based post-combustion carbon capture (PCC) is a mature and essential technology to solve the global warming problem. The high energy consuming issue and the flexible operation required by the power plants inquire about the development of effective control systems for PCC plants. This study proposes the optimal-based control approach that utilizes optimal set-point values for the quality controllers. The five optimal-based control schemes studied all employed $\mathrm{L} / \mathrm{G}$ (liquid to gas ratio in absorber) as one quality control variable. Performance comparisons with a typical conventional control scheme are conducted employing a rate-based dynamic model for the MEA (monoethanolamine) solvent PCC process developed on a commercial process simulator. Compared to the typical control scheme, the optimal-based control schemes provide faster responses to the disturbance changes from the flue gas conditions and the set-point change of the $\mathrm{CO}_{2}$ capture efficiency, as well as better results in terms of IAEs (integral of absolute errors) of capture efficiency and reboiler heat duty during the stabilization period. $\mathrm{LG}-\mathrm{T}_{\text {str }}$ and $\mathrm{LG}-\mathrm{T}_{\mathrm{abs}}-$ Cascade are the best schemes. In addition to $\mathrm{L} / \mathrm{G}$, these two schemes employ the control of $\mathrm{T}_{\text {str }}$ (the temperature of a stage of stripper) and a cascade control of $\mathrm{T}_{\mathrm{abs}}$ (the temperature of a stage of absorber) (outer loop) and $\mathrm{T}_{\text {str }}$ (inner loop), respectively.
\end{abstract}

Keywords: post-combustion; solvent-based carbon capture; process control; rate-based model; Aspen Custom Modeler ${ }^{\circledR}$

\section{Introduction}

Carbon capture and storage (CCS) is a critical $\mathrm{CO}_{2}$ emission abatement technology. Based on a CCS facility with a $\mathrm{CO}_{2}$ capture capacity of 1.5 million tonnes per annum (Mtpa), 2500 CCS facilities must be operated in 2040 to meet the Paris $2{ }^{\circ} \mathrm{C}$ target [1]. Post-combustion $\mathrm{CO}_{2}$ capture (PCC) using amine-based solvent is considered a mature technology for $\mathrm{CO}_{2}$ capture and is likely to be the first carbon capture technology to be deployed worldwide on a large scale [2]. The advantages of amine-based PCC include its suitability for retrofitting to existing fossil fuel-fired power plant and the ability to treat flue gas flows with low $\mathrm{CO}_{2}$ concentration [3]. Nonetheless, the issues of large energy requirement, typically around $15-30 \%$ of the net power generated of a coal-fired power plant [4], must be resolved before large-scale deployment of PCC technology becomes a reality. In addition to alternative process configurations and optimal operation conditions [5-8], the attention to efficiency improvements in PCC technology has been extended toward effective control of PCC and the flexible operation strategies of the power plant integrated with its PCC plant [2].

On the basis of researches for stand-alone PCC plants, including the development of dynamic model, model validation using pilot plant data, and investigation of various control structures, many recent publications contribute to the development of linked dynamic process simulation models and study of control strategies for the flexible operation of the integrated thermal power plant and PCC 
process. Ziaii et al. [9] developed a dynamic model of a monoethanolamine (MEA)-based absorption process and a steady-state model of the turbine section of a coal-fired power plant to evaluate control strategies for part-load operation or the power plant and a reduction of reboiler load. The open loop response study concluded that the control strategy using a ratio controller to adjust the circulation solvent flow rate with the reboiler heat rate allows the maintaining of lean loading and results in the increase of $\mathrm{CO}_{2}$ removal by $1 \%$ with fast response. For a coal-fired power plant, Wellner et al. [10] analyzed a case scenario of reducing the steam extraction of the carbon capture process by $50 \%$ using a PCC model validated by the steady and transient data of a pilot plant in Heilbronn, Germany and a dynamic model of the power plant. The PCC runs in feed-forward operation and by actuating reboiler steam valve fast and reliable power control can be obtained. Montañés et al. [11] linked dynamic models of power plant, gas turbine, steam turbine, and PCC process to study the load-change transient performance of a commercial-scale natural gas combined cycle power plant. The power plant model was validated against steady-state data, and the PCC model was validated using steady-state and transient data from a large-scale amine pilot plant [12]. Five control schemes of PCC were evaluated for the change of gas turbine load from $100 \%$ to $70 \%$ with different ramp rate. The control scheme controlling the L/G (liquid to gas ratio) of the absorber gives significantly faster stabilization times to the power plant and PCC unit's main process variables. Garđarsdóttir et al. [13] investigated the transient performance of two operation modes, various power plant loads and levels of steam availability, for the integrated system of a supercritical pulverized-coal-fired power plant with a $\mathrm{CO}_{2}$-absorption process. The five control schemes for the PCC process employ the $\mathrm{CO}_{2}$ capture rate, $\mathrm{L} / \mathrm{G}$, and reboiler temperature as controlled variables and the flow rates of steam, lean solvent, and rich solvent as manipulated variables. With these control schemes, the load-change operation mode can be well controlled, while stable operations are not attainable for varying steam availability operation. Martinez Castilla et al. [14] conducted a modeling study of open-loop responses of the $\mathrm{CO}_{2}$ capture process integrated into an industrial combined-heat-and-power plant with load changes. Using a dynamic PCC model validated by the pilot plant operated at Maasvlakte power station in Netherlands, Sharifzadeh and Shah [15] investigated the controllability of the integrated power plant and capture process, for which the design and operation of the capture process have been optimized simultaneously [16]. The control scheme controls the extent of $\mathrm{CO}_{2}$ capture, reboiler temperature, and lean solvent temperature entering the absorber with lean solvent flow rate, steam flow rate, and cooling water flow rater, respectively. The results of 155 sensitivity analyses suggested a high degree of controllability and flexibility for both natural gas and coal-fired scenarios [15].

In these studies, on the flexible operation of the integrated power plant and PCC process, the dynamic models of the PCC process employed were developed and validated independently to the power plant model. Based on their analysis results, Montañés et al. [11] and Garđarsdóttir et al. [13] both concluded that $\mathrm{CO}_{2}$-absorption process has much slower dynamics than the power plant cycle. Hence, an effective control scheme of the PCC process is highly critical to the controllability and flexibility of the integrated system [13]. As the PCC process is associated with the power plant only through two boundary conditions, i.e., the flue gas inlet stream and the reboiler steam, the structure of control schemes for the integrated power plant and PCC process and that of the stand-alone PCC process are the same. The identified effective control schemes considering appropriate boundary conditions for the stand-alone PCC process can be expected to work well for the integrated power plant and PCC process.

For the control of stand-alone PCC processes, Panahi and Skogestad $[4,17]$ emphasized on the optimal operation of PCC with the optimality defined in terms of a cost function that includes energy consumption and the penalty for the release of $\mathrm{CO}_{2}$ to air. The proposed self-optimizing control concept is that the process is indirectly close to its optimum when the control variables are held constant at their optimal normal set-points. By a top-down approach, the self-optimal controlled variables (CVs) are identified as the percentage of $\mathrm{CO}_{2}$ capture $(\% \mathrm{CC})$ in the absorber and the temperature of a tray in stripper $\left(\mathrm{T}_{\text {str }}\right)$ or the reboiler duty $\left(\mathrm{Q}_{\mathrm{reb}}\right)$ and $\mathrm{T}_{\text {str }}$ for different regions of operation. For the major 
disturbances of the system, i.e., the flue gas flowrate and $\mathrm{CO}_{2}$ concentration, a bottom-up approach was then taken to test the performance of different pairing among CVs and manipulated variables (MVs). In addition to decentralized control, they also implemented the MPC (model predictive control) for comparison. The performance comparison was based on the tightness of CVs to their target values and the economic objective function values at the final steady state. They concluded that the best control parings (CV-MV) are \%CC- $\mathrm{Q}_{\text {reb }}$ and $\mathrm{T}_{\text {str }}-\mathrm{F}_{\text {rich }}$ (rich solvent flow rate into the stripper) and has performance comparable to MPC.

Nittaya et al. [18] proposed three control schemes developed from RGA (Relative Gain Array) analysis approach or heuristic approach, including (A) \%CC- $\mathrm{Q}_{\mathrm{reb}}$ and $\mathrm{T}_{\text {reb }}-\mathrm{F}_{\text {lean }}$ (reboiler temperature-lean solvent flow rate into the absorber); (B) \%CC- $\mathrm{F}_{\text {lean }}$ and $\mathrm{T}_{\mathrm{reb}}-\mathrm{Q}_{\mathrm{reb}}$; (C) \%CC- $\mathrm{Q}_{\text {reb }}$ and $\mathrm{T}_{\text {reb }}-\mathrm{F}_{\text {rich }}$. These control schemes were evaluated using different scenarios, namely the changes in the $\mathrm{CO}_{2}$ capture set-points, operating conditions of flue gas stream, and stiction of the outlet valve of the buffer tank. The performance evaluation was based on ISE of \%CC (Integrated-Squared-Error of \%CC against its set point) and the integrated reboiler energy requirement. Because the assumption of the RGA analysis did not take into account the process dynamics, the control structure (A) based on RGA analysis did not provide good performance. The control structures $B$ and $C$ obtained from the heuristic approach resulted in shorter closed-loop settling time.

For the integrated natural gas-fueled combined cycle power plant and PCC process, Montañés et al. [19] reported experimental results of open-loop responses and performance of several decentralized control structures for load changes at the larger scale amine pilot plant at Technology Centre Mongstad. The tests adopted control schemes with $\mathrm{L} / \mathrm{G}$ ratio control and with $\mathrm{CO}_{2}$ capture rate control, specifically, include (A) $\mathrm{T}_{\text {reb }}-\mathrm{Q}_{\mathrm{reb}}$ and keeping $\mathrm{L} / \mathrm{G}$ ratio to a fixed value manually; (B) $\% C C-\mathrm{F}_{\text {rich }}$ and $\mathrm{T}_{\text {reb }}-\mathrm{Q}_{\mathrm{reb}}$; (C) \%CC- $F_{\text {rich }}$ and manually adjusting $Q_{\text {reb. }}$. The study concluded that fast and large changes in the solvent flow rate as a control measure could cause instabilities due to the interaction between the stripper temperature and the capture rate control loops. They suggested a combination of feedforward and feedback algorithms could be a solution to achieve fast and stable disturbance rejections.

Two valuable insights can be drawn from these studies on the control strategies of PCC plants. The first one is the need to pursue the optimal control and operation with the objective function defined in terms of energy consumption or cost of operation. For example, Panahi and Skogestad $[4,17]$ proposed a method to identify the self-optimal controlled variables; Gjernes et al. [20] developed U-curves in the experimental tests for the $\mathrm{CO}_{2}$ capture unit of Technology Center Mongstad and identified the optimal stripper bottom temperature and lean loading of MEA solvent for minimum specific reboiler duty. The second one is that it is necessary to adjust the operation conditions, such as the solvent flowrate or reboiler steam flowrate, with the changes in loading (e.g., the flow rate or $\mathrm{CO}_{2}$ concentration of flue gas) or set-point (e.g., the percentage or amount of $\mathrm{CO}_{2}$ capture). For these adjustments, Montañés et al. [11,12] suggested the adoption of feedforward control and implemented manually in their experimental study. The choice of the L/G of absorber as a controlled variable [9] actually implies this adjustment. However, in those studies $[11,13]$ that adopted L/G as a controlled variable, even for a significant level of power plant load change cases, a fixed-value L/G set-point determined for the baseline operation, instead of the optimal value for the actual flue gas inlet conditions, was used.

The rigorous simulation model developed from first principles is an indispensable and economic tool for the design and operation of amine-based PCC process. Due to the rate-controlled chemical reactions and the heat and mass transfer, a significant difference in accuracy between equilibriumand rate-based models was found [21]. Steady-state rate-based model for chemical absorption has been developed and provided as a standard module (Radfrac) in the commercial process simulation software package Aspen Plus ${ }^{\circledR}$ [22]. However, the Radfrac column model does not export to Aspen Plus Dynamics ${ }^{\circledR}$. Dynamic rate-based models have been developed on other software platforms, such as gPROMS ${ }^{\circledR}[18,23,24]$, Matlab $^{\circledR}[25]$, and UniSim ${ }^{\circledR}$ [17]. The dynamic models developed on the Aspen Plus ${ }^{\circledR}$ platform are either only for the stripper column [9] or equilibrium-based [26]. 
Using the steady-state, rate-based Aspen Plus ${ }^{\circledR}$ model, Zhang et al. [27] established correlations of murphy efficiencies to develop the dynamic model in the Aspen Plus Dynamics ${ }^{\circledR}$. Bui et al. [2] provided an extensive literature review of the simulation scenarios and characteristics of various dynamic models. Some dynamic models have undergone validation against dynamic pilot plant data $[12,25,28,29]$. Recently, the authors of this paper [30] developed a rate-based dynamic model for the MEA (monoethanolamine) solvent PCC process on the Aspen Custom Modeler ${ }^{\circledR}$ (ACM) software platform [31]. The model was validated using the dynamic pilot plant from [25].

In this study, the performance of several control schemes with optimal operation conditions as the controller set-points is analyzed employing the rate-based dynamic model for the stand-alone MEA solvent PCC process developed on the ACM software platform [30]. In addition to the dynamic response and settling time, the performance of control schemes in terms of the integrated absolute error (IAE) during the transient-period for the absorption efficiency, amount of $\mathrm{CO}_{2}$ emission and reboiler heat duty are compared. In the discussion of the flexible operation of the integrated power plant and PCC process, scenarios with up to $50 \%$ load changes are investigated [13,19]. In this paper, the scope of the study is limited to the control of a stand-alone PCC with disturbance and set-point changes around the nominal base load operation $( \pm 10 \%)$.

\section{Process and Simulation}

The $\mathrm{CO}_{2}$ capture process studied is illustrated in Figure 1. The major units were the absorber for flue gas $\mathrm{CO}_{2}$ absorption into the MEA solution and the stripper with a steam reboiler and a condenser for the regeneration of the MEA solution and producing the gaseous product, which consists of only $\mathrm{CO}_{2}$ and water. Other units were auxiliary equipment, including the cross heat exchanger for heat recovery from the lean solution leaving the stripper to the rich solution leaving the absorber, a cooler to further cool the lean solution before entering the absorber, and a surge tank to buffer the solution flow between the absorber and stripper. Due to the limitation of feasible column diameter, five parallel lines were needed. The gas treated in the absorber was $1 / 5$ of the flue gas generated by a $300 \mathrm{MWe}$ coal-fired power plant, and the $\mathrm{CO}_{2}$ concentration was $14.6 \mathrm{vol} \%$. The absorption liquid was a $30 \mathrm{wt} \%$ MEA aqueous solution. The $\mathrm{CO}_{2}$ capture efficiency was $90 \%$, and the stripper operation pressure was 2 bar. Both the absorber and stripper employed the Sulzer BX structured packing.

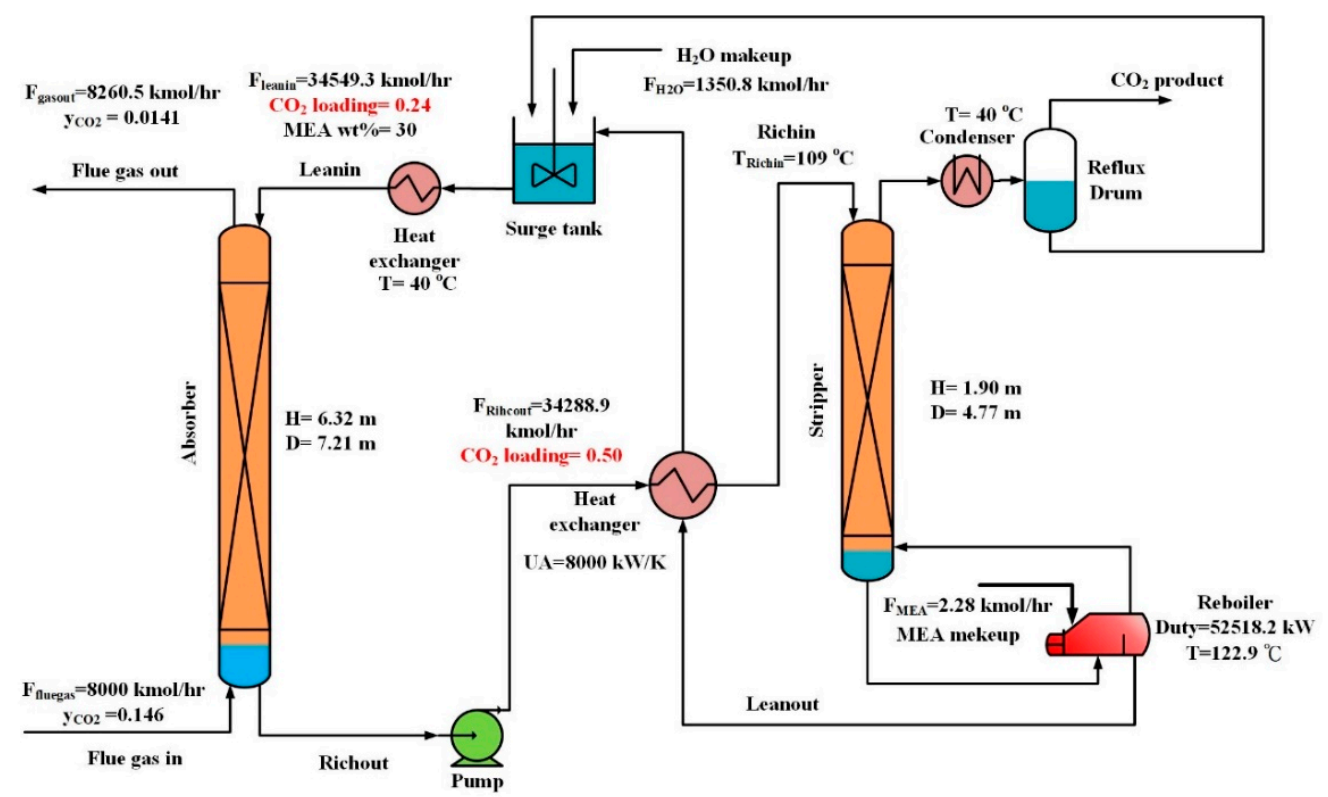

Figure 1. The $\mathrm{CO}_{2}$ capture process using monoethanolamine (MEA) solvent for a coal-fired power plant. 
The $\mathrm{CO}_{2}$ capture process, as shown in Figure 1, was simulated using the unit and flowsheet models built on ACM by the authors of this paper. The modeling details and model validation are presented in [29]. The rate-based column model developed for absorber and stripper took into account the heat and mass transfer across the vapor-liquid interface, as well as the enhancement of $\mathrm{CO}_{2}$ absorption by the liquid phase chemical reactions.

For this study, the equipment sizes specified are depicted in Figure 1. For the base operation conditions, based on the design in Flø et al. [25] and the level control stability in our simulation, the holdup volume of absorber sump, reboiler sump, condenser reflux drum, and surge tank corresponded to the residence time of $5 \mathrm{~min}, 20 \mathrm{~min}, 5 \mathrm{~min}$, and $30 \mathrm{~min}$, respectively.

\section{Steady-State Optimization}

The control approach proposed in this study was based on the optimal operation conditions with the objective of minimizing the specific heat duty $\left(\overline{\mathrm{Q}}_{\mathrm{reb}}\right)$, i.e., the reboiler heat duty for one kmole of $\mathrm{CO}_{2}$ captured. Therefore, a steady-state optimization analysis for the process operated under the studied disturbances or new set-points must be conducted before the investigation of proposed control schemes and their performance. The optimization study was implemented by combining parametric analysis and optimal search using ACM. The parametric analysis varied the flow rate $\left(\mathrm{F}_{\text {Flue gas }}\right), \mathrm{CO}_{2}$ concentration $\left(\mathrm{y}_{\mathrm{CO} 2}\right)$, and temperature ( $\left.\mathrm{T}_{\text {Flue gas }}\right)$ of the inlet flue gas, the lean loading of solvent (LL), and the $\mathrm{CO}_{2}$ capture efficiency (\%CC). For each set of these operation parameters, the minimum specific reboiler duty $\left(\overline{\mathrm{Q}}_{\mathrm{reb}}\right)$ was determined, employing the optimization solver of ACM. The decision variables $(D)$ were the solvent flow rate $\left(\mathrm{F}_{\text {Leanin }}\right)$, reboiler duty $\left(\mathrm{Q}_{\mathrm{reb}}\right)$, and the makeup flowrates of water $\left(\mathrm{F}_{\mathrm{H} 2 \mathrm{O}, \mathrm{MU}}\right)$ and MEA $\left(\mathrm{F}_{\mathrm{MEA}, \mathrm{MU}}\right)$. The optimization problem conducted in ACM is defined as:

$$
\begin{gathered}
\min _{\mathrm{D}} \overline{\mathrm{Q}}_{\mathrm{reb}} \\
\mathrm{D}=\left\{\mathrm{F}_{\text {Leanin }}, \mathrm{Q}_{\mathrm{reb}}, \mathrm{F}_{\mathrm{MEA}, \mathrm{MU}}, \mathrm{F}_{\mathrm{H} 2 \mathrm{O}, \mathrm{MU}}\right\}
\end{gathered}
$$

Subject to:

$$
\begin{gathered}
f(X, S)=0 \\
\% C C=\% C C_{\text {fixed }}, C_{M E A}=30 w t \%, L L=L_{\text {fixed }} \\
F_{\text {Flue gas }}=F_{\text {Fluegas, fixed }}, y_{C O 2}=y_{C O 2, f i x e d}, T_{\text {Flue gas }}=T_{\text {Fluegas, fixed }}
\end{gathered}
$$

where $\mathrm{f}$ is the rate-based process model as a function of state variables $\mathrm{X}$ and equipment size variables $\mathrm{S}$. Note that the equipment sizes are fixed.

For the disturbance changes of flue gas flow rate, $\mathrm{CO}_{2}$ concentration, and temperature, as well as the set-point change of $\mathrm{CO}_{2}$ capture efficiency, the optimal solutions for different lean loading of solvent are summarized in Figure 2. For all the flue gas conditions or capture efficiency, the optimal $\mathrm{L} / \mathrm{G}$ increased with the lean loading. In other words, when employing higher lean loading, the higher circulation rate of solvent is required. The optimal $\mathrm{L} / \mathrm{G}$ increased with the flue gas flow rate and concentration, as well as the capture efficiency. The flue gas temperature had an only minor effect on the optimal L/G. The specific heat duty also increased with the flue gas flowrate and capture efficiency, but the effects of flue gas concentration and temperature were insignificant. All the curves in Figure $2 b, d, f, h$ show a minimum specific heat duty at lean loading of 0.24 . This result suggests that this process, with the given equipment sizes, should be operated at lean loading of 0.24 . The optimal value of $\mathrm{L} / \mathrm{G}$ for each operation case, for example, at certain flue gas flow rate, concentration, and temperature or certain capture efficiency, is employed in the control schemes, as discussed in Section 4. 


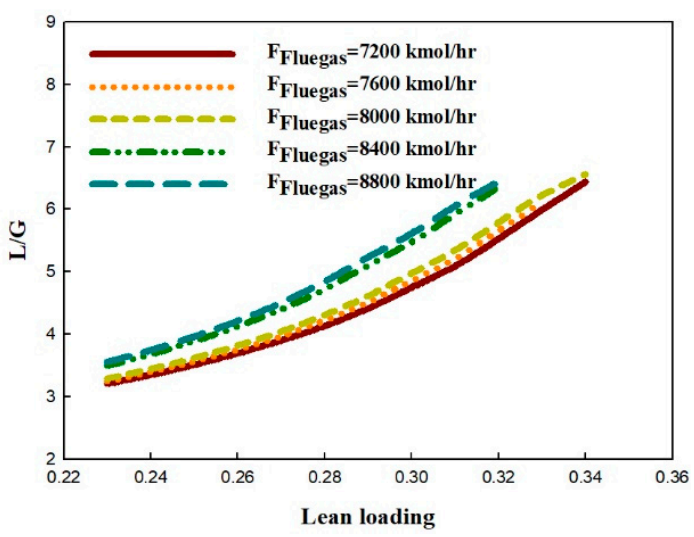

(a)

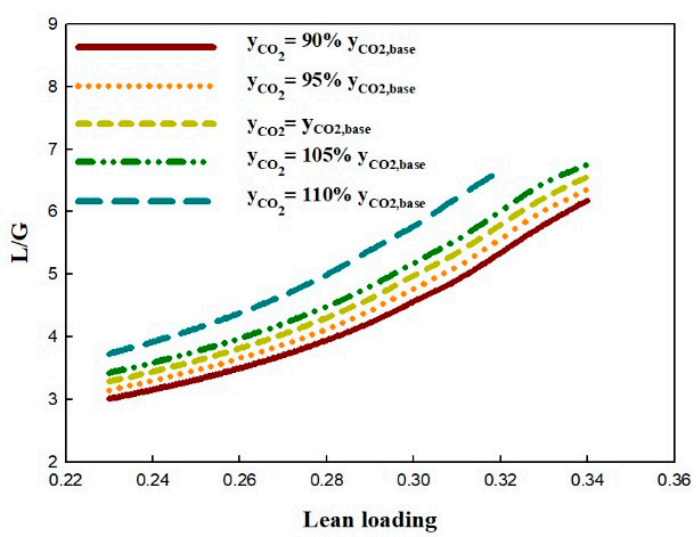

(c)

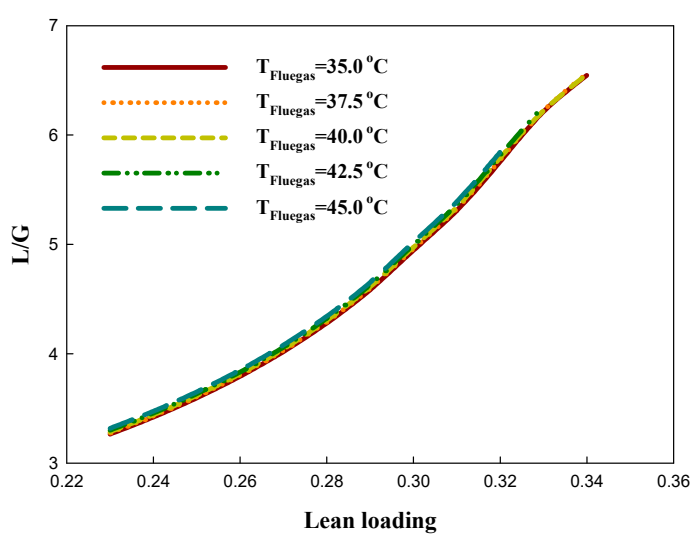

(e)

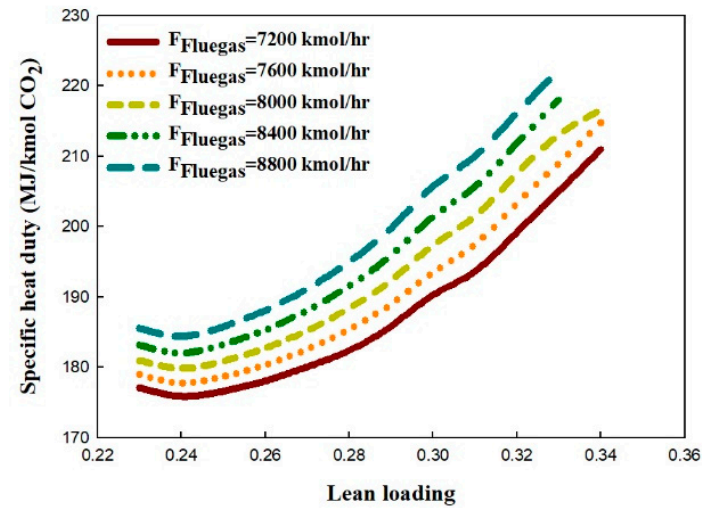

(b)

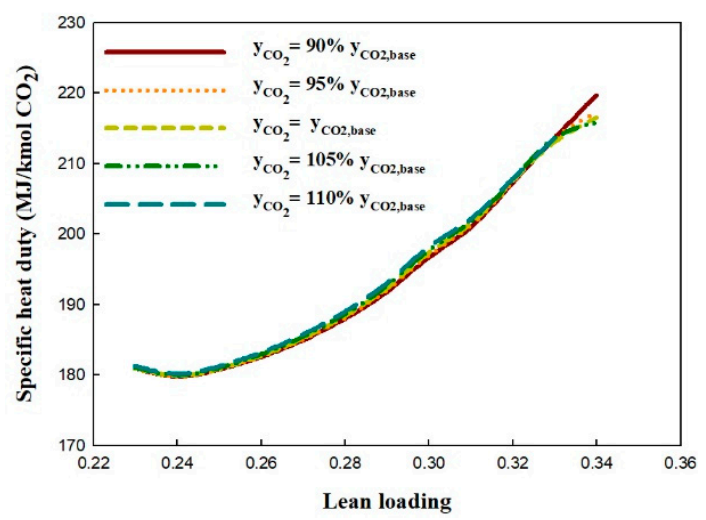

(d)

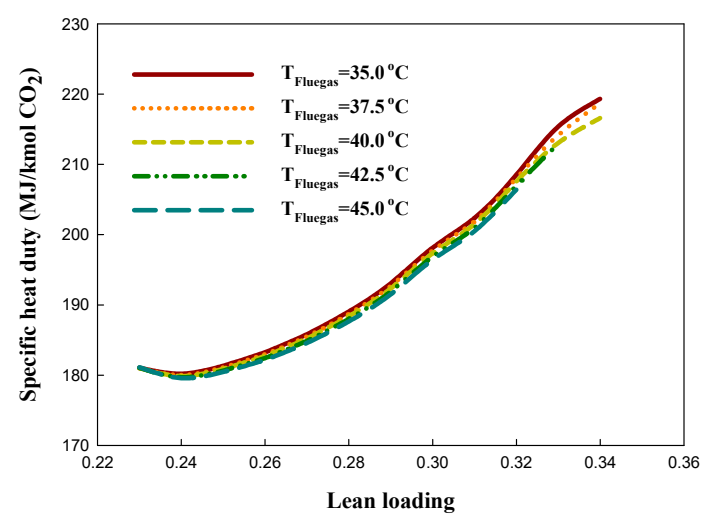

(f)

Figure 2. Cont. 


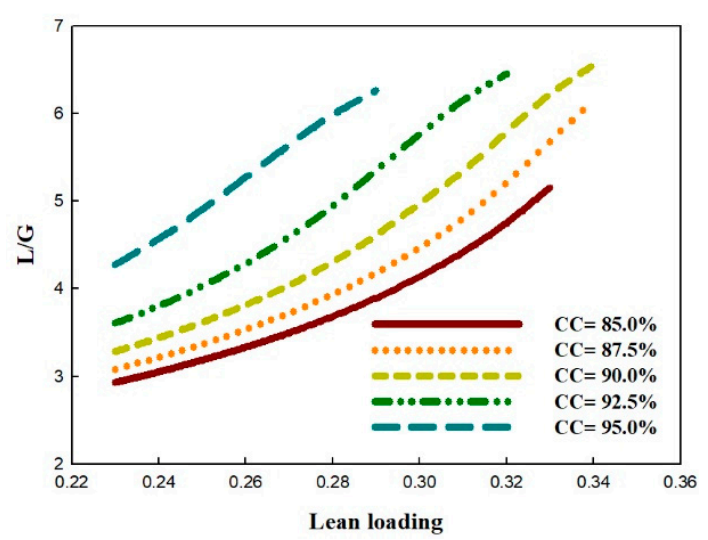

(g)

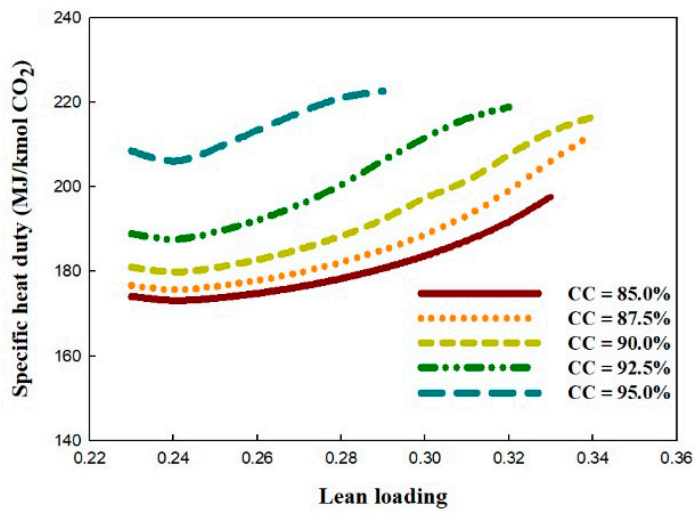

(h)

Figure 2. Optimal solutions for the operations for flue gas conditions (flow rate, $\mathrm{CO}_{2}$ concentration, and temperature) and capture efficiency changes under different lean loading of solvent in terms of L/G and specific reboiler duty. (a) L/G-flue gas flowrate change; (b) specific heat duty-flue gas flowrate change; (c) L/G-flue gas concentration change; (d) specific heat duty-flue gas concentration change; (e) L/G-flue gas temperature change; (f) specific heat duty-flue gas temperature change; (g) L/G-capture efficiency change; (h) specific heat duty-capture efficiency change.

\section{Control Schemes and Controller Parameters}

The manipulated variables, for which control valves can be employed to adjust their values, available to the PCC process, are listed in Table 1 and depicted in Figure 3a. The seven valves, V1 V7, can be employed to set up the five inventory control loops and two quality control loops. The matches of manipulated and controlled variables for inventory control are listed in Table 1. Note that the pressure control loops of absorber and stripper, which correspond to the inventory control of the gases of the two columns, were assumed to be under perfect control with the outlet flue gas flow and $\mathrm{CO}_{2}$ product flow, respectively. Therefore, the pressure control was not included in the following discussion. The lean amine cooler and the stripper condenser are both operated using cooling water. Because of the fast dynamic responses relative to other controllers in the process, these two temperature controllers were assumed to be under perfect control and were not included in the control schemes. For all the control schemes studied in this paper, the inventory control loops are all the same. In other words, the control schemes are different only in their quality control loops.

Table 1. Manipulated and controlled variables available for configuring control structures.

\begin{tabular}{|c|c|}
\hline Manipulated Variable & Controlled Variable \\
\hline \multicolumn{2}{|c|}{ Inventory Control } \\
\hline Absorber rich outflow rate $\left(\mathrm{F}_{\text {richout }}\right)(\mathrm{V} 1)$ & Absorber sump liquid level ( $\left.\mathrm{L}_{\mathrm{abs}}\right)$ \\
\hline Stripper lean outflow rate $\left(\mathrm{F}_{\text {leanout }}\right)(\mathrm{V} 3)$ & Stripper sump liquid level ( $\left.\mathrm{L}_{\mathrm{str}}\right)$ \\
\hline Reflux drum condensate flow rate $\left(\mathrm{F}_{\text {cond }}\right)(\mathrm{V} 2)$ & Reflux drum liquid level ( $\left.\mathrm{L}_{\text {refluxdrum }}\right)$ \\
\hline Makeup $\mathrm{H}_{2} \mathrm{O}$ flow rate $\left(\mathrm{F}_{\mathrm{H} 2 \mathrm{O}, \mathrm{mu}}\right)(\mathrm{V} 4)$ & Surge tank liquid level ( $\left.\mathrm{L}_{\text {surgetank }}\right)$ \\
\hline Makeup MEA flow rate $\left(\mathrm{F}_{\mathrm{MEA}, \mathrm{mu}}\right)(\mathrm{V} 5)$ & Solvent MEA concentration ( $\left.\mathrm{C}_{\mathrm{MEA}}\right)$ \\
\hline \multicolumn{2}{|c|}{ Quality control } \\
\hline Absorber lean inflow rate $\left(\mathrm{F}_{\text {leanin }}\right)(\mathrm{V} 6)$ & $\mathrm{CO}_{2}$ capture efficiency $(\% \mathrm{CC})$ \\
\hline Reboiler heat duty $\left(\mathrm{Q}_{\mathrm{reb}}\right)(\mathrm{V} 7)$ & Lean loading (LL) \\
\hline & Stripper temperature $\left(\mathrm{T}_{\mathrm{str}}\right)$ \\
\hline & Absorber temperature $\left(\mathrm{T}_{\mathrm{abs}}\right)$ \\
\hline & Liquid to gas ratio in the absorber (LG) \\
\hline
\end{tabular}


The two manipulated variables left for the quality control were the lean solvent flow rate and the reboiler heat duty. However, the controlled variables for the quality control could be the $\mathrm{CO}_{2}$ capture efficiency (\%CC), lean solvent $\mathrm{CO}_{2}$ loading (LL), temperature of a certain stage of absorber $\left(\mathrm{T}_{\mathrm{abs}}\right)$, temperature of a certain stage of stripper $\left(\mathrm{T}_{\mathrm{str}}\right)$, or the liquid to gas ratio in the absorber (LG). The control approach taken by this study was to utilize optimal operation conditions and L/G. Five control schemes were hence proposed. The control schemes, symbolized by the two controlled variables selected for the quality control and shown in Figure 3b-f, include LG-CC, LG-LL, LG-Tabs, LG- $T_{\text {str }}$, and LG- $T_{a b s}-$ Cascade. The control scheme of $L G-T_{a b s}-$ Cascade employs a cascade structure using $\mathrm{T}_{\mathrm{str}}$ and $\mathrm{T}_{\mathrm{abs}}$ as the inner-loop and outer-loop controlled variables, respectively. To serve as a benchmark for the performance evaluation of the proposed optimal-based control schemes, a typical control structure using CC and $T_{\text {str }}$ as the controlled variables $[4-6,15,17,18]$ with fixed set-point values was included in this study. The typical control scheme is shown in Figure 3a. For the schemes employing the absorber temperature $\left(T_{a b s}\right)$ as a controlled variable, the temperature of stage 6 (counted from top) of the absorber was chosen, which is the stage having the highest temperature. For the schemes adopting the stripper temperature $\left(\mathrm{T}_{\mathrm{str}}\right)$ as a controlled variable, as shown in Figure $3 \mathrm{a}, \mathrm{e}, \mathrm{f}$, the temperature of stage 17 (counted from top) of the stripper was chosen, which is the stage most sensitive to the reboiler duty determined by a sensitivity analysis with different reboiler duty. Note that for the packed-type absorber and stripper, the total height of the column packing is equally discretized into 20 stages in the simulation study. As shown in Figure 3c, the bottom concentration of the stripper, instead of the concentration of the lean solvent entering the absorber, was used as the controlled variable of the lean loading control loop. This arrangement allows for faster adjustment of the reboiler steam flow rate for the variation of the stripper bottom concentration.

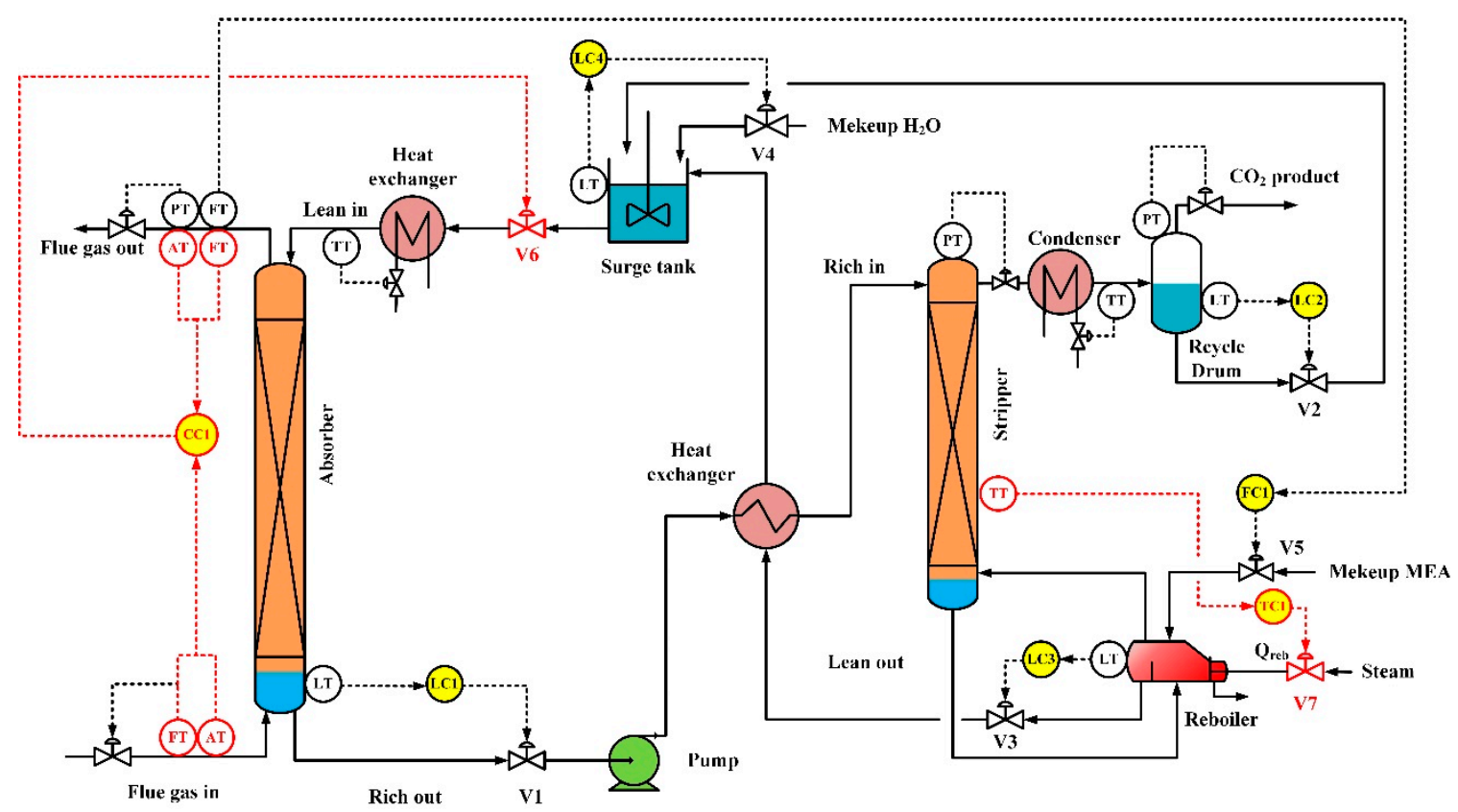

(a)

Figure 3. Cont. 


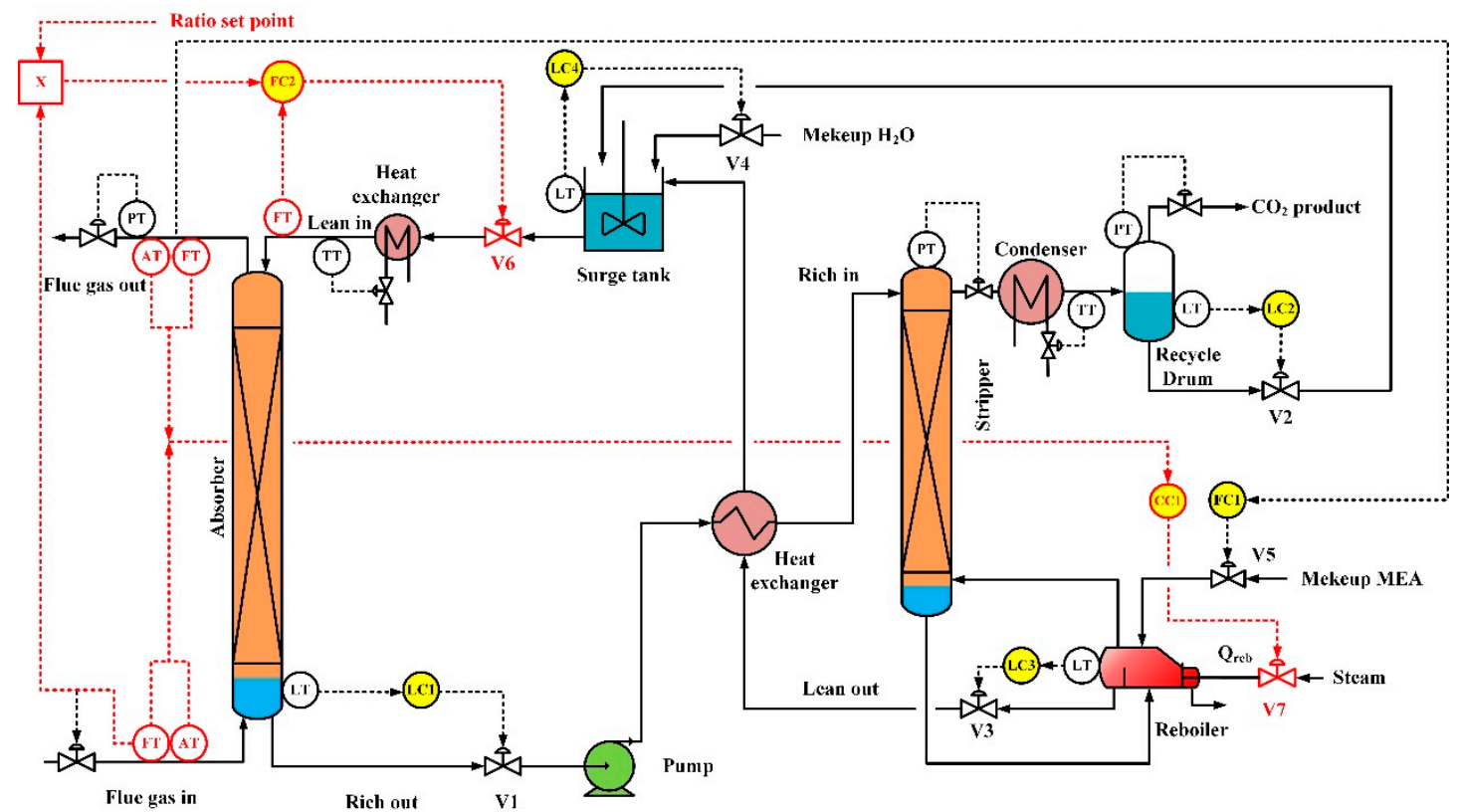

(b)

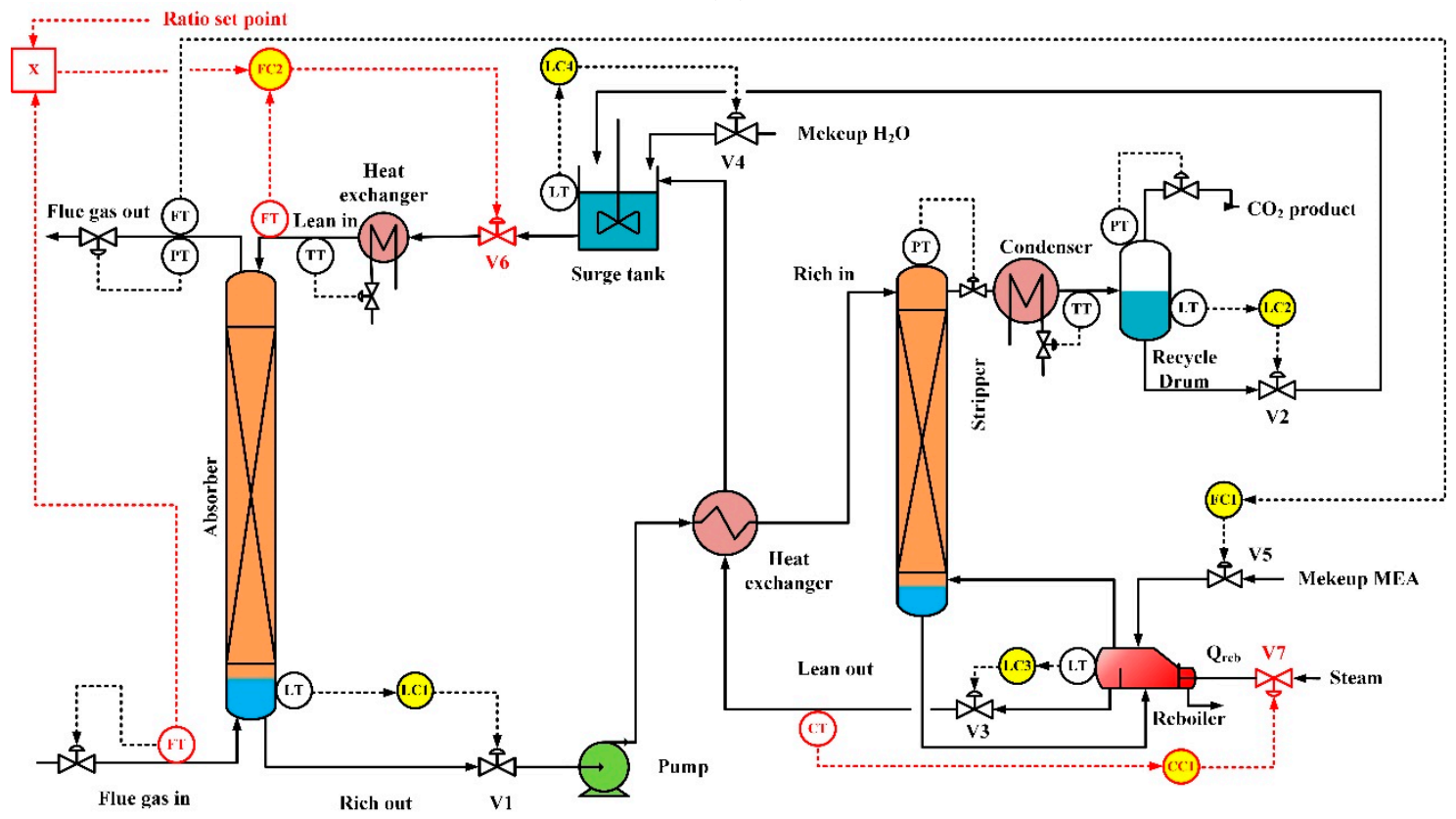

(c)

Figure 3. Cont. 


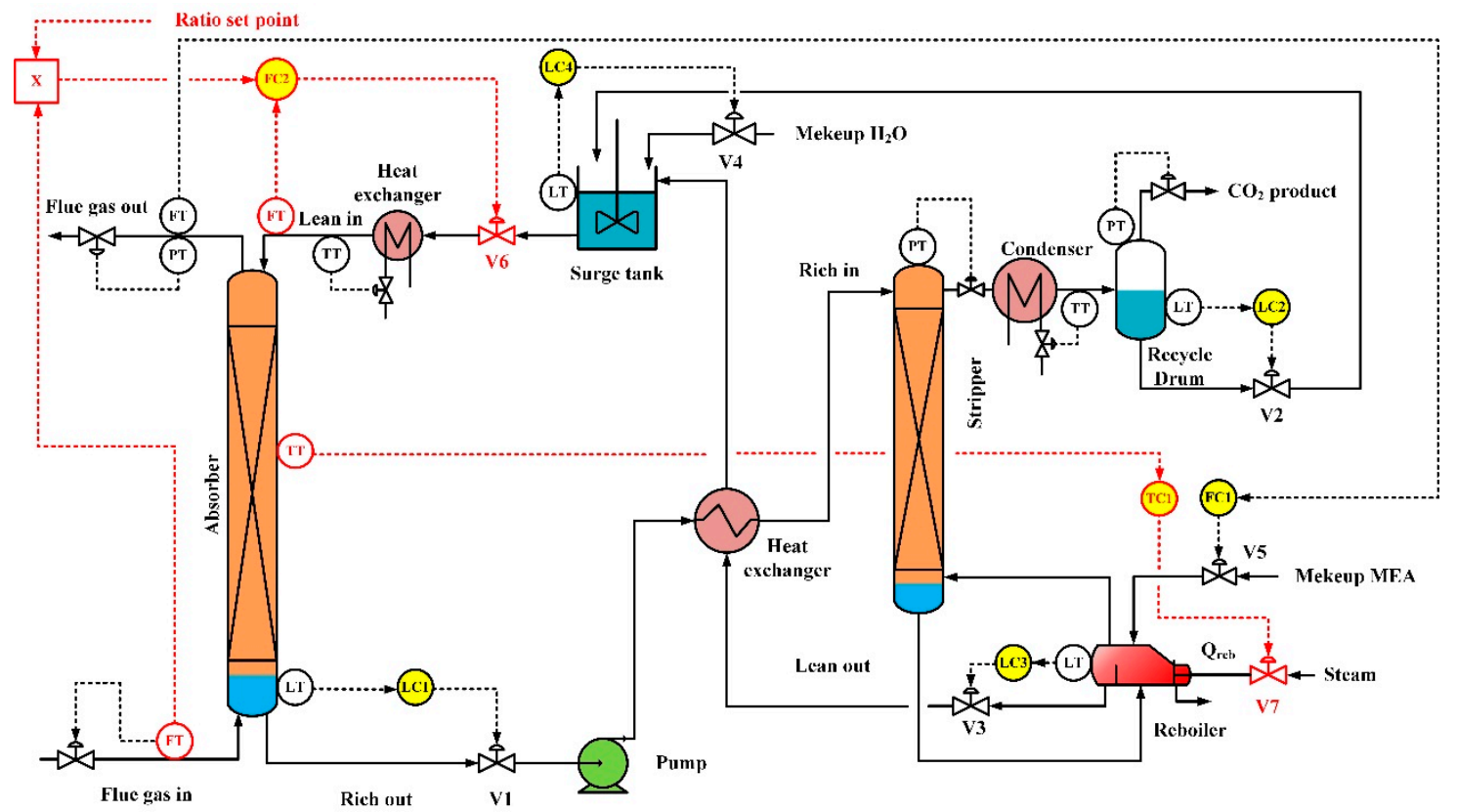

(d)

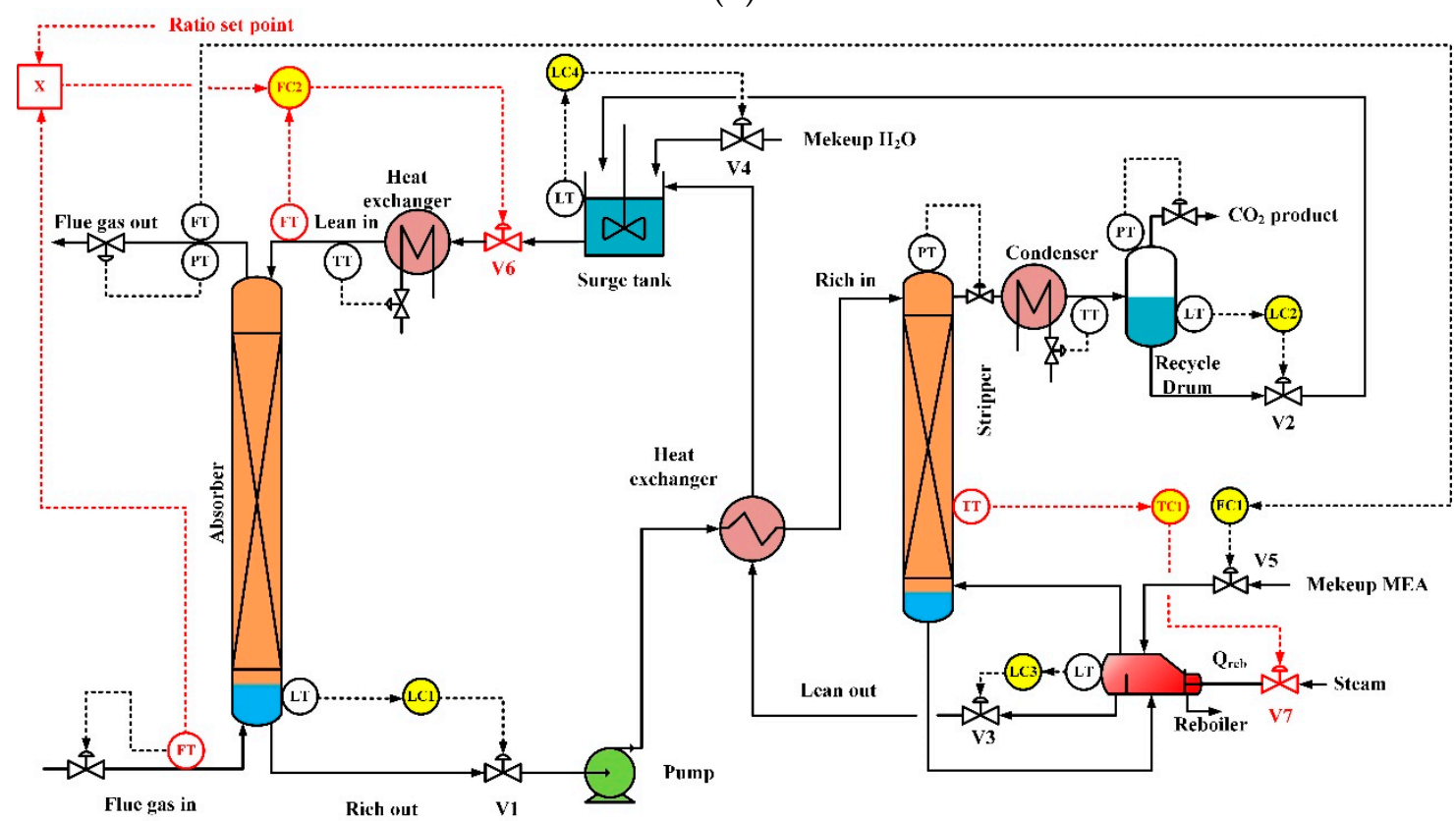

(e)

Figure 3. Cont. 


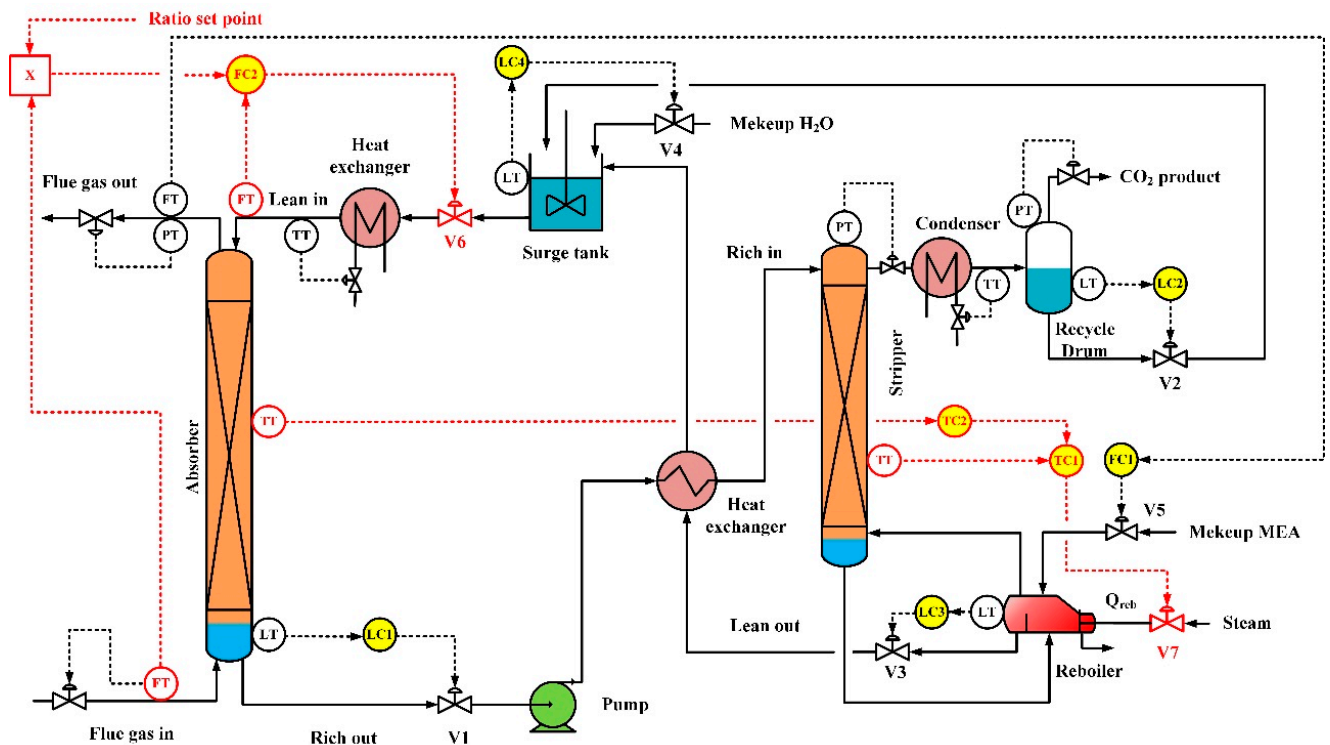

(f)

Figure 3. Control schemes proposed for the PCC process where scheme (a) is a typical one and schemes (b-f) are based on optimal operation conditions. The inventory control loops are the same in all control schemes. The two quality control loops in each control scheme are shown in red. The disturbances of $\pm 10 \%$ around base load case are studied. (a) CC-T $\mathrm{T}_{\text {str }}$; (b) LG-CC; (c) LG-LL; (d) LG-T $\mathrm{T}_{\mathrm{abs}}$; (e) LG-T $\mathrm{T}_{\text {str }}$; (f) $\mathrm{LG}-\mathrm{T}_{\mathrm{abs}}$-Cascade. LG: liquid to gas ratio; $\mathrm{T}_{\mathrm{str}}$ : the temperature of a stage of a stripper; $\mathrm{T}_{\mathrm{abs}}$ : the temperature of a stage of the absorber.

The tuning parameters using literature suggested values [32] or determined by open-loop IMC (Internal Model Control) method [33] for the PID (Proportional-Integral-Derivative) controllers of all the control schemes are listed in Table 2. Dead times of $6.5 \mathrm{~min}$ were used in all composition loops, and two first order lags of $0.5 \mathrm{~min}$ were used in all temperature loops [32].

Table 2. Tuning parameters of the Proportional-Integral-Derivative (PID) controllers for the same inventory controllers used for all control schemes and for the quality controllers of each control scheme.

\begin{tabular}{cccc}
\hline Controllers and Control Schemes & Gain & Integral Time (min) & Derivative Time (min) \\
\hline Level controllers for all schemes $^{1}$ & 2.0 & - & - \\
Flow controllers for CC-T ${ }_{\text {str }}{ }^{2}$ & 1.54 & 32.5 & 0.1 \\
Flow controllers for other schemes & 0.5 & 0.3 & - \\
Temperature controllers & & & - \\
CC-T & & 17.74 & - \\
LG-CC & 0.87 & 231.81 & - \\
LG-LL & 26.59 & 139.54 & - \\
LG-T & 1.25 & 4.66 & - \\
LG-T & 6.17 & 62.65 & - \\
LG- abs $_{\text {abs }}-$ Cascade & 1.74 & 143.84 & - \\
\hline
\end{tabular}

Notes: ${ }^{1}$. Luygen and Luygen [32]; ${ }^{2}$. Internal Model Control (IMC) method. CC: capture capacity, LG: liquid to gas ratio, $\mathrm{T}_{\mathrm{str}}$ : the temperature of a stage of a stripper, $\mathrm{T}_{\mathrm{abs}}$ : the temperature of a stage of the absorber, Cascade: cascade control structure.

\section{Results and Discussion}

In this section, the control performance of the studied control schemes to the disturbances of flue gas conditions, including its flowrate, $\mathrm{CO}_{2}$ concentration, and temperature, as well as the set-point change of $\mathrm{CO}_{2}$ capture efficiency, are presented and compared. The performance discussed include the dynamic responses and the IAEs (integral of absolute error) of capture efficiency and reboiler heat duty during the stabilization period. 


\subsection{Dynamic Responses}

In this study, the disturbance or set-point changes are achieved by a step change at the time of $1 \mathrm{~h}$. For all the control schemes employing CC (capture efficiency) for quality control, i.e., $\mathrm{CC}-\mathrm{T}_{\text {str }}$ and LG-CC, the set-point value of the CC controller is only adjusted for the cases of capture efficiency set-point change. For the typical control scheme CC- $\mathrm{T}_{\text {str }}$, the set-point value of $\mathrm{T}_{\mathrm{str}}$ is fixed for all the disturbance or set-point changes. For all the other five control schemes (Figure $3 b-f$ ), termed as the optimal-based control schemes, the set-point values of the controlled variables for quality control, i.e., $\mathrm{L} / \mathrm{G}, \mathrm{LL}, \mathrm{T}_{\mathrm{abs}}$, and $\mathrm{T}_{\mathrm{str}}$, are adjusted to their optimal values at the same time as the disturbance or set-point change starts. Note that the optimal values of these controlled variables have been obtained from the steady-state optimization analysis, presented in Section 3. By this analysis approach, it implies that feedforward control is available to provide the information of disturbance changes. In this study, the dynamics of the feedforward control is not included in the simulation.

For the disturbance and set-point change cases studied, including the $\pm 10 \%$ disturbance change of the flue gas flow rate $( \pm 800 \mathrm{kmol} / \mathrm{h}), \pm 10 \%$ disturbance change of the flue gas $\mathrm{CO}_{2}$ concentration $( \pm 1.46 \mathrm{vol} \%), \pm 12.5 \%$ disturbance change of the flue gas temperature $\left( \pm 5^{\circ} \mathrm{C}\right)$, and the set-point change of $\mathrm{CO}_{2}$ capture efficiency from $90 \%$ to $85 \%, 87.5 \%, 92.5 \%$, and $95 \%$, the complete results of the dynamic responses are provided in the Supplementary Materials due to the length limitation of this paper. In the following, the results of one disturbance change case and one set-point change case are discussed.

\subsubsection{Disturbance in Flue Gas}

For the $10 \%$ increase of flue gas flow rate, the dynamic responses of concentration-control related schemes, i.e., $\mathrm{LG}-\mathrm{CC}$ and LG-LL, and the temperature-control related schemes, i.e., $\mathrm{LG}-\mathrm{T}_{\mathrm{abs}}, \mathrm{LG}-\mathrm{T}_{\text {str }}$, and LG- $\mathrm{T}_{\mathrm{abs}}$-Cascade, are compared to the typical control scheme CC- $\mathrm{T}_{\text {str }}$ in Figure $4 \mathrm{a}, \mathrm{b}$, respectively. The characteristics revealed are summarized as below.

- Capture efficiency: For all the control schemes, the capture efficiency sharply dropped to about $85 \%$ following the step increase of flue gas flow rate. For all the optimal-based control schemes, the capture efficiency recovers to $90 \%$ with obviously less time and less deviation from the target value than the CC- $\mathrm{T}_{\text {str }}$ control scheme.

- Reboiler heat duty: The LG-CC control responses to the initial drop of capture efficiency with an initial drastic escalation of reboiler duty because of the CC control loop. On the contrary, LG- $\mathrm{T}_{\mathrm{abs}}$ and LG- $\mathrm{T}_{\mathrm{abs}}$-Cascade both responses with an initial drastic decrease of reboiler duty because of the control of $\mathrm{T}_{\mathrm{abs}}$, which is quickly raised due to the greater amount of absorption resulted from the higher flue gas flow rate.

- Solvent flow rate: For all the optimal-based control, L/G is controlled and set to its optimal value when the disturbance occurs. On the other hand, the $\mathrm{CC}-\mathrm{T}_{\text {str }}$ scheme responses with a slow increase in solvent flow rate to a higher than optimal final value.

- Solvent loadings: For all the optimal-based schemes, the response of lean loading is stronger than that of rich loading, while the opposite is true for the CC- $\mathrm{T}_{\text {str }}$ scheme. For the CC- $\mathrm{T}_{\text {str }}$ scheme, the set-point of stripper temperature is not adjusted with the disturbance change; hence, it results in a smoother change in lean loading. However, the final steady value of lean loading deviates from the optimal value, i.e., 0.24 . For all the optimal-based schemes, the new steady state can approach the optimal value.

- Temperatures: Temperature-control related schemes show temperature responses with less damping, expect LG-T $\mathrm{T}_{\mathrm{abs}}$. In LG- $\mathrm{T}_{\mathrm{abs}}$, reboiler heat duty is manipulated to control $\mathrm{T}_{\mathrm{abs}}$, and longer response time is needed due to the involvement of many units in the control loop. When the modified scheme, i.e., $\mathrm{LG}-\mathrm{T}_{\mathrm{abs}}$-Cascade, is employed, the temperature responses are much improved. 

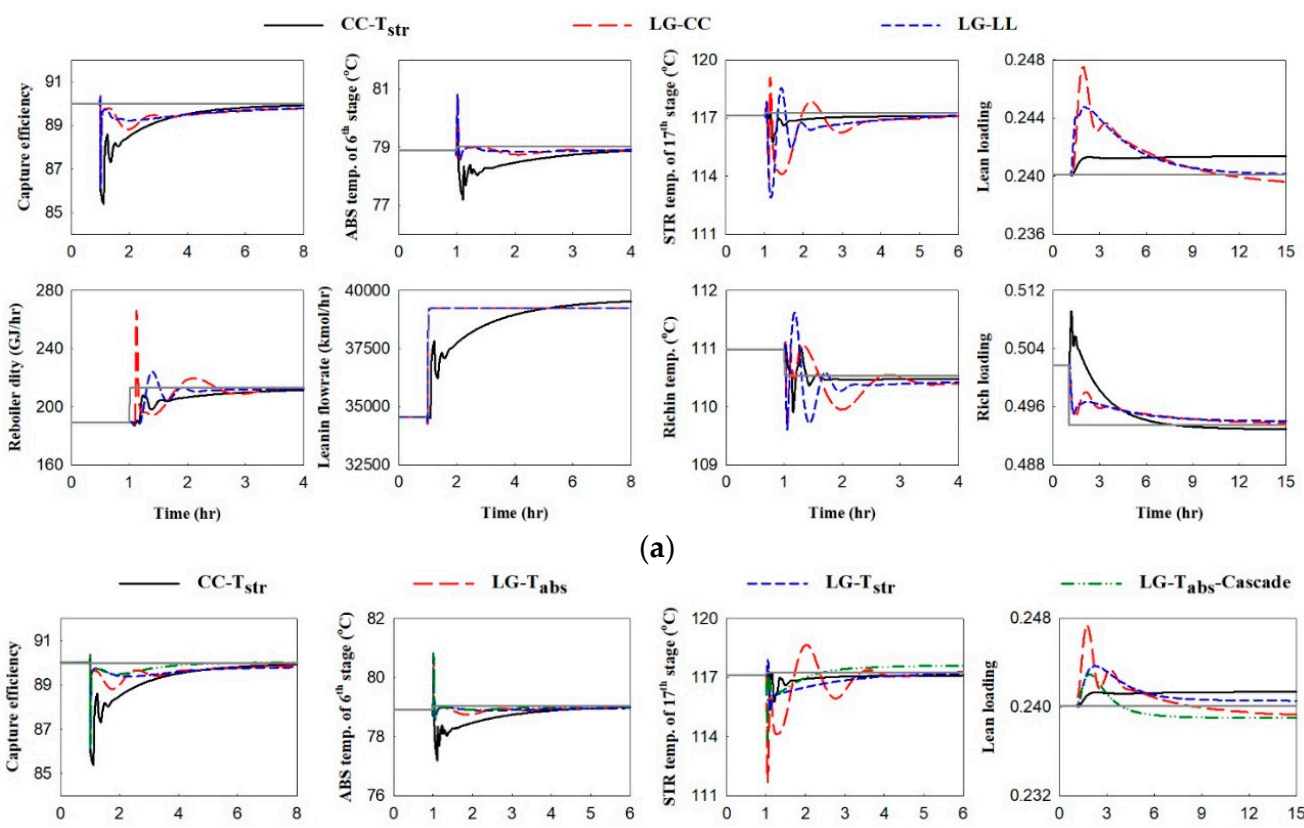

(a)
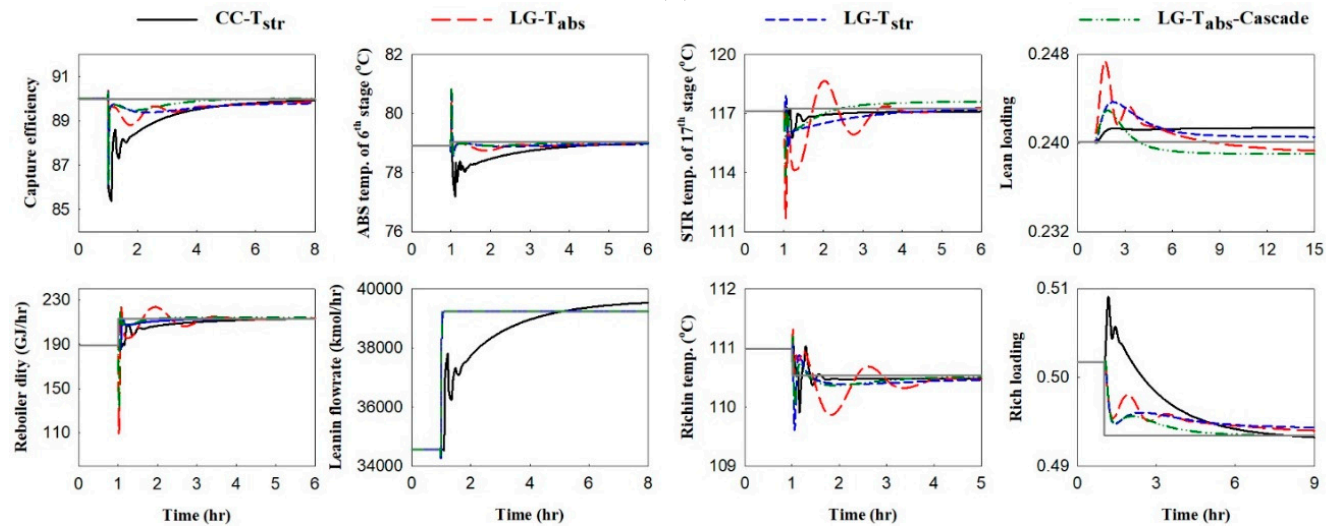

(b)

Figure 4. Dynamic responses for disturbance of flue gas flow rate with a $10 \%$ increase. The subfigures show the responses of the controlled variables (capture efficiency, lean loading, absorber temperature, and stripper temperature) and major process variables (lean solvent flow rate, reboiler duty, and the loading and temperature of the rich solvent). In both figures $(\mathbf{a}, \mathbf{b})$, the traditional control scheme $\left(\mathrm{CC}-\mathrm{T}_{\text {str }}\right)$ responses are included for comparison. For all the control schemes, the original capture efficiency can be restored with the same reboiler duty at the new steady state. (a) concentration-control related schemes; (b) temperature-control related schemes.

Due to the minor effects on the process, the disturbance change of flue gas temperature can be easily controlled by all the control schemes, as shown in the Supplementary Information.

\subsubsection{Capture Efficiency Set-Point Change}

For the set-point change of $\mathrm{CO}_{2}$ capture efficiency from $90 \%$ to $92.5 \%$, the dynamic responses of concentration-control related schemes and the temperature-control related schemes are compared to the typical control scheme CC- $\mathrm{T}_{\text {str }}$ in Figure $5 \mathrm{a}, \mathrm{b}$, respectively. The characteristics revealed are summarized as below.

- Capture efficiency: The capture efficiency can quickly reach the target value with all the optimal-based control schemes; however, the typical control scheme responds very slowly. Within the optimal-based control schemes, the responses of LG- $T_{a b s}$ and LG-CC show more significant damping.

- Reboiler heat duty: In order to obtain fast responses, the optimal-based control schemes require much higher reboiler heat duty with noteworthy damping than the CC- $\mathrm{T}_{\text {str }}$ control scheme at the initial period of time.

- Solvent flow rate: For all the optimal-based control, $L / G$ is controlled and set to its optimal value at the same time when the set-point change of the capture efficiency is set. The solvent flow rate of CC- $\mathrm{T}_{\text {str }}$ scheme increases very slowly to a higher than optimal final value. 
- Solvent loadings: For all the optimal-based schemes, the lean loading responses with more significant damping than the rich loading, while the CC- $\mathrm{T}_{\text {str }}$ scheme responds slowly for both lean and rich loadings. For the CC- $\mathrm{T}_{\text {str }}$ scheme, the final steady value of lean loading deviates from the optimal value, i.e., 0.24 .

- Temperatures: Temperature-control related schemes show temperature responses with less damping, expect $\mathrm{LG}-\mathrm{T}_{\mathrm{abs}}$. In LG- $\mathrm{T}_{\mathrm{abs}}$, as explained above, the long reacting time of the $\mathrm{T}_{\mathrm{abs}}$ control loop results in a highly damping response. While the modified LG- $\mathrm{T}_{\text {abs }}$-Cascade scheme provides much better control.
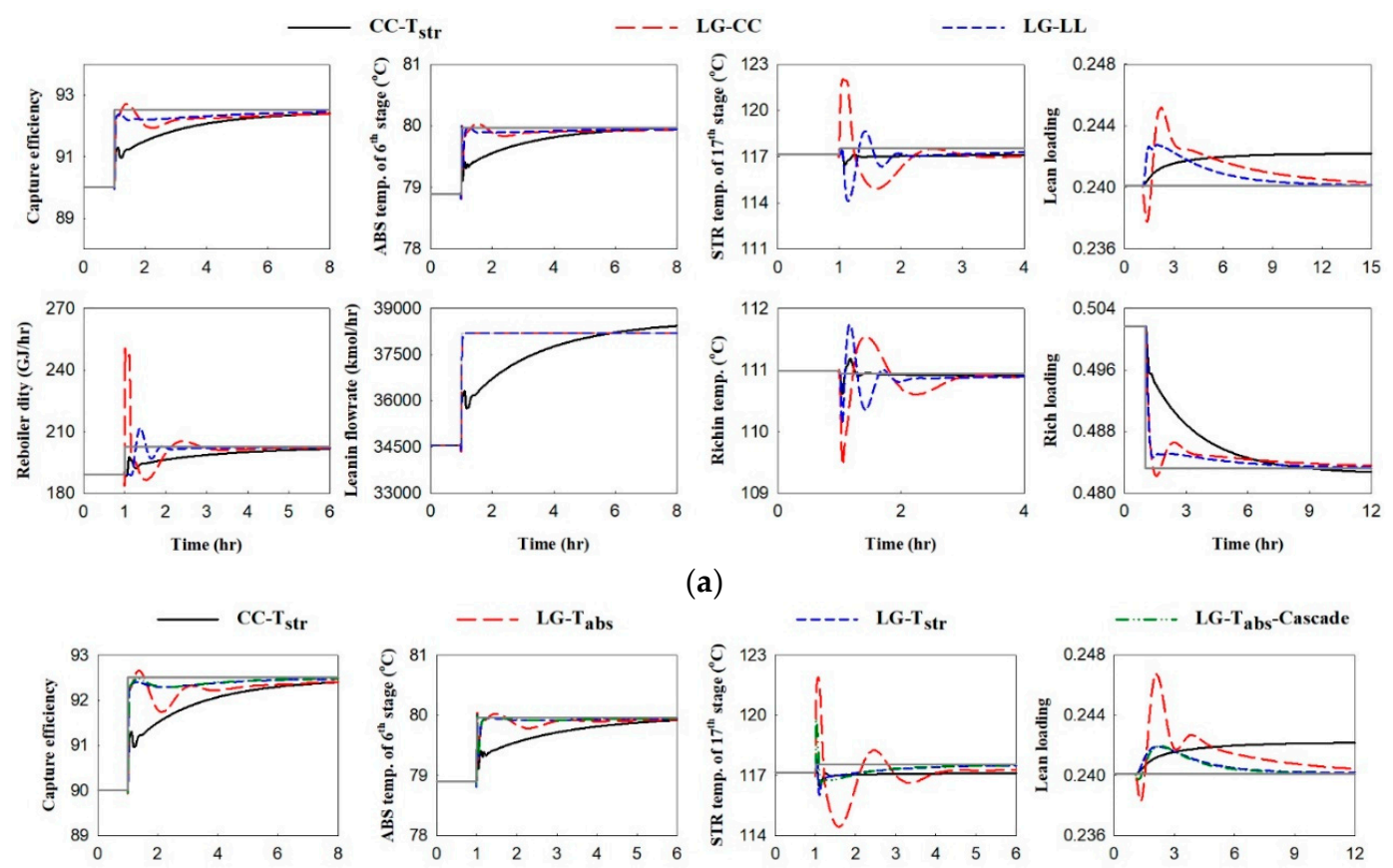

(a)
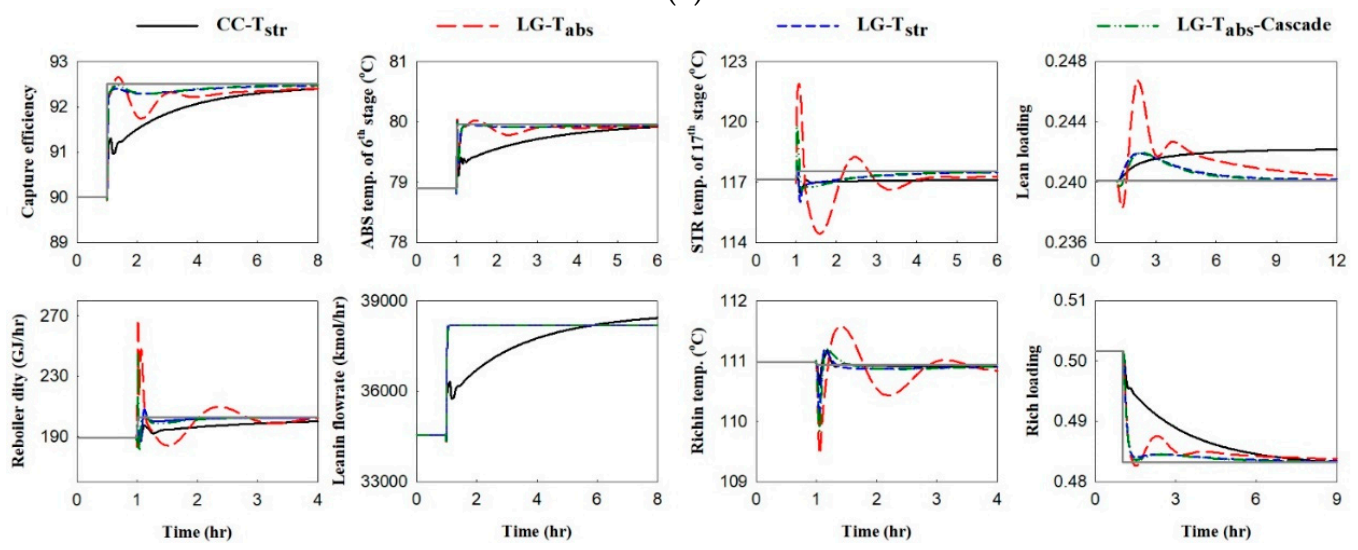

(b)

Figure 5. Dynamic responses for set-point change of $\mathrm{CO}_{2}$ capture efficiency from $90 \%$ to $92.5 \%$. The subfigures show the responses of the controlled variables (capture efficiency, lean loading, absorber temperature, and stripper temperature) and major process variables (lean solvent flow rate, reboiler duty, and the loading and temperature of the rich solvent). In both figures (a) and (b), the traditional control scheme $\left(\mathrm{CC}-\mathrm{T}_{\mathrm{str}}\right)$ responses are included for comparison. For all the control schemes, the new capture efficiency set-point can be met with the same reboiler duty at the new steady state.

(a) concentration-control related schemes; (b) temperature-control related schemes.

Note that for the set-point change of capture efficiency to the highest value of $95 \%$, feasible operation results can only be obtained for the control schemes of CC- $\mathrm{T}_{\text {str }}, \mathrm{LG}-\mathrm{LL}$, and $\mathrm{LG}-\mathrm{T}_{\text {str }}$. For other control schemes, the simulation problem might be caused by the controller-action-requested operation conditions, which fall outside the limited operation ranges or converged solutions cannot be found. Feasible operation is also not attainable for the set-point change of capture efficiency to $85 \%$ while employing $\mathrm{LG}-\mathrm{T}_{\mathrm{abs}}$ control scheme. For the equipment sizes and operation ranges determined for the capture efficiency of $90 \%$, it is easier to face converge problems for a greater extent of capture efficiency changes, i.e., the set-point value of $85 \%$ or $95 \%$. 
On the dynamic responses, we can conclude:

- For all the concentration-related optimal-based control schemes, employing the CC or LL control, the capture efficiency or lean loading can be well controlled.

- For all the temperature-related optimal-based control schemes, except LG- $\mathrm{T}_{\mathrm{abs}}$, the temperatures of the absorber, stripper, and rich solvent entering the stripper can be well controlled.

- For all the control schemes, including the optimal-based and the typical, the capture efficiency set-point can be closely approached for disturbance changes and most of the set-point change cases.

- For both disturbance and set-point changes, more significant damping responses are observed for LG- $T_{a b s}$ and LG-CC control schemes. The RGA analysis results [34] confirm that inappropriate matches are used by these two schemes. The inferior performance of these two control schemes can also be explained by the longer path between the controlled variable and manipulated variable.

\subsection{Stabilization Period Performance}

The studied control schemes are further compared for the deviation from final target capture efficiency and reboiler heat duty during the stabilization period. The deviation is evaluated by the integral absolute error (IAE) defined for the capture efficiency and reboiler heat duty as:

$$
\begin{aligned}
& \% \mathrm{CC}_{\mathrm{IAE}}=\int_{\mathrm{t}_{0}}^{\mathrm{t}_{\mathrm{f}}}\left|\% \mathrm{CC}_{\mathrm{t}}-\% \mathrm{CC}_{\text {set-point }}\right| \mathrm{dt} \\
& \mathrm{Q}_{\mathrm{reb}, \text { IAE }}=\int_{\mathrm{t}_{0}}^{\mathrm{t}_{\mathrm{f}}}\left|\mathrm{Q}_{\text {reb,t}}-\mathrm{Q}_{\text {reb,target }}\right| \mathrm{dt}
\end{aligned}
$$

The integral time interval starts from the time disturbance or set-point change $\left(\mathrm{t}_{0}=1 \mathrm{~h}\right)$ and ends at a fixed long enough time $\left(t_{f}\right)$, which is $15 \mathrm{~h}$ and $20 \mathrm{~h}$ for the disturbance change and set-point change, respectively.

For the disturbance changes of flue gas conditions, the IAEs of \%CC and $\mathrm{Q}_{\mathrm{reb}}$ of the control schemes are compared in Figure $6 \mathrm{a}, \mathrm{b}$. Considering the closeness of capture efficiency to the target value, $\mathrm{LG}-\mathrm{T}_{\text {abs }}$-Cascade is the best control scheme, while $\mathrm{LG}-\mathrm{T}_{\text {str }}$ gives the closest reboiler heat duty profile to the optimal heat duty corresponding to the new flue gas conditions. Relative to the typical control scheme CC- $\mathrm{T}_{\text {str }}$, each of the optimal-based control schemes is superior in terms of closer capture efficiency or reboiler heat duty. Within the optimal-based control scheme, $\mathrm{LG}-\mathrm{T}_{\mathrm{abs}}$ gives the worst outcome in the IAE of $Q_{\text {reb }}$.

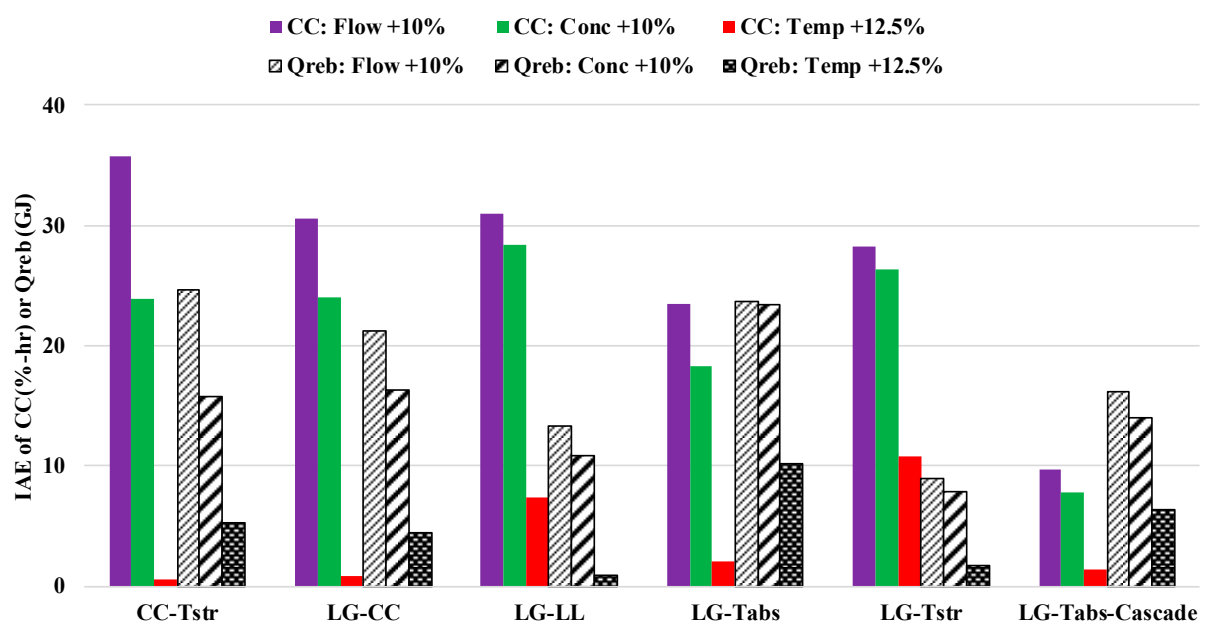

(a)

Figure 6. Cont. 


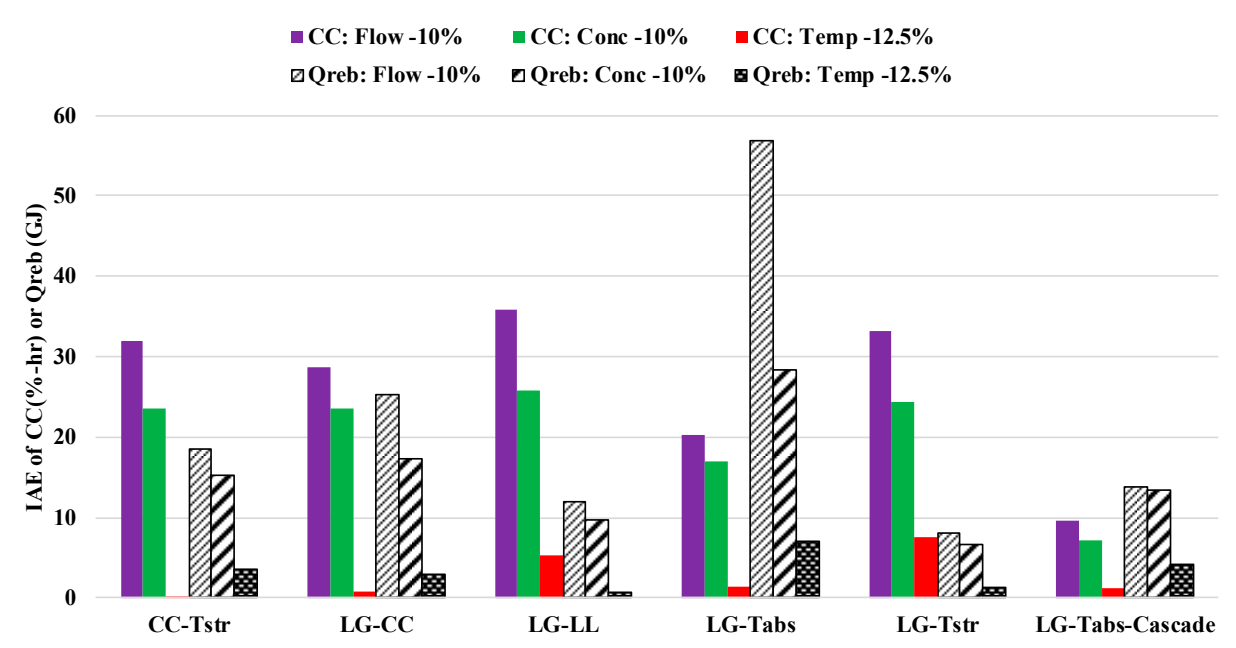

(b)

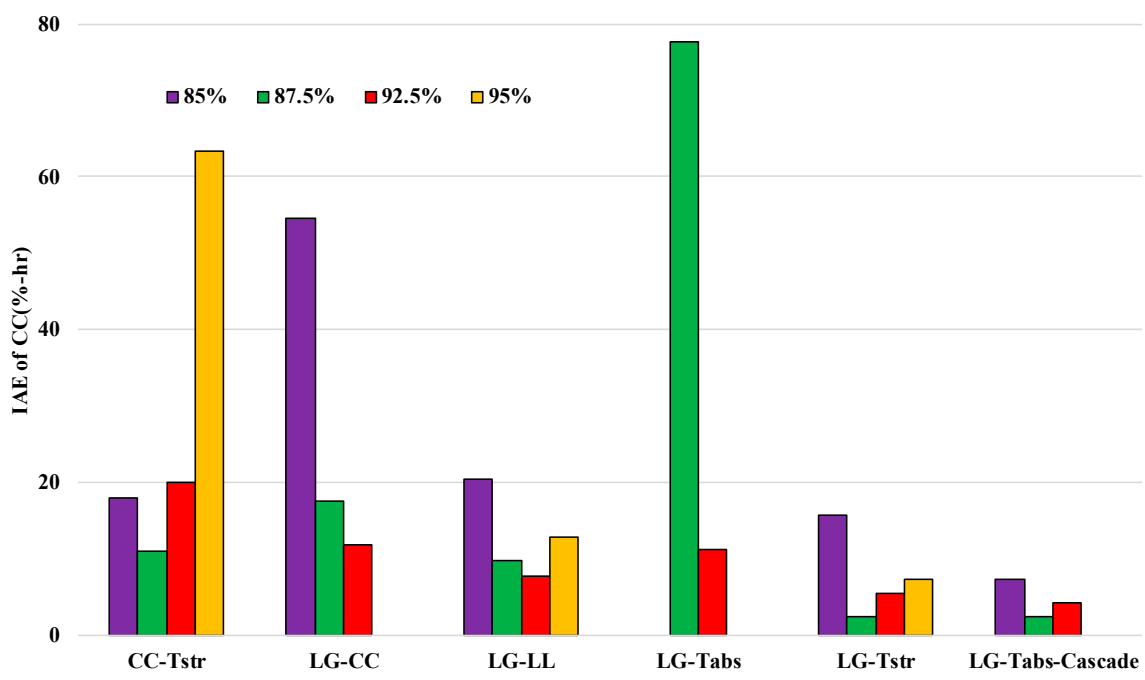

(c)

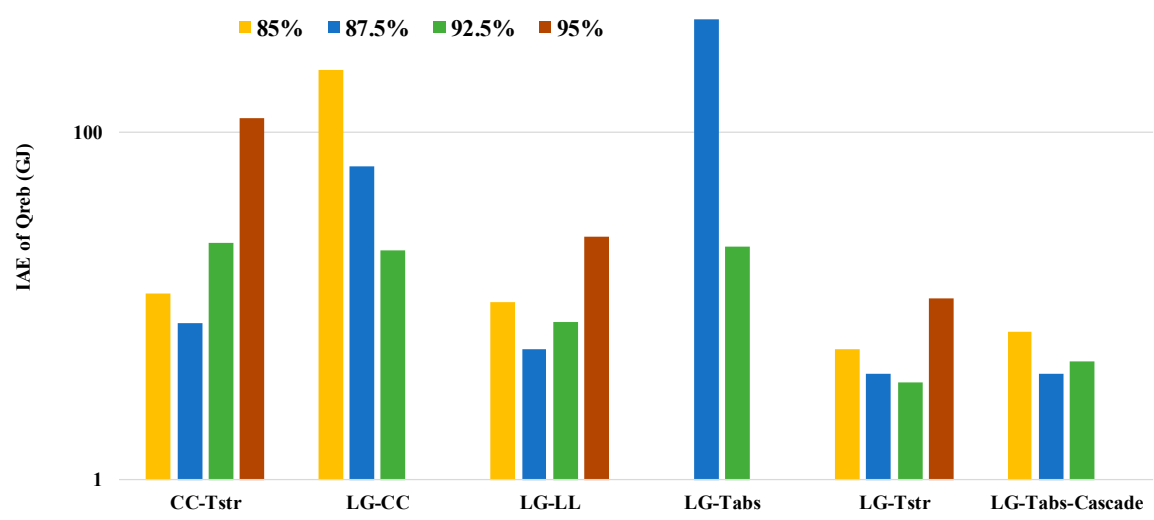

(d)

Figure 6. Integral of absolute errors (IAEs) of $\mathrm{CO}_{2}$ capture efficiency (CC) and reboiler heat duty $\left(\mathrm{Q}_{\mathrm{reb}}\right)$ during the stabilization period for disturbance and set-point changes. A higher value of IAE indicates a greater extent deviation from the target capture efficiency or a higher reboiler duty demand. (a) Increase of flue gas conditions; (b) decrease of flue gas conditions; (c) IAE of \%CC for set-point change of $\mathrm{CO}_{2}$ capture efficiency; (d) IAE of $\mathrm{Q}_{\mathrm{reb}}$ for set-point change of $\mathrm{CO}_{2}$ capture efficiency (in logarithm scale). 
For the set-point change of capture efficiency, the IAEs of $\% C C$ and $Q_{\text {reb }}$ of the control schemes are compared in Figure $6 c, d$, respectively. Note that the figures show only the cases for which converged simulation results are available. Based on these IAE results, $L G-T_{\text {str }}$ and $L G-T_{\text {abs }}-$ Cascade are the best schemes for the set-point change control. Same as for the disturbance change control, $\mathrm{LG}-\mathrm{T}_{\mathrm{abs}}$ is the worst optimal-based scheme for the set-point change control.

\subsection{Effect of Model Error}

Evaluation of the effect of model accuracy on the control performance is essential to ensure the validity of the above comparison and discussion on the studied control schemes. In this study, the evaluation is conducted for disturbance change cases by testing the effect of $\pm 5 \%$ error on the optimal value of $\mathrm{L} / \mathrm{G}$, which is used as the set-point value of the $\mathrm{LG}$ controller in the optimal-based control schemes. The effect compared is the deviation of the final capture efficiency from the set-point value, i.e., $90 \%$. The results for all the disturbance change cases are summarized in Table 3. Note that the 'accurate' case represents when there is no error in the model. For a few cases, converged dynamic simulation results cannot be obtained due to too stringent tolerance settings. Although the deviation of capture efficiency from the cases with a model error is higher than the case without model error, the deviation results are all less than $2 \%$. Therefore, the results and discussion of control schemes' comparison presented in the above sections are valid if reasonable model accuracy can be assumed.

Table 3. Effect of model error on the deviation of $\mathrm{CO}_{2}$ capture efficiency (\%) by testing $\pm 5 \%$ error on the optimal values of the controlled variables.

\begin{tabular}{|c|c|c|c|c|c|}
\hline Case & LG-CC & LG-LL & LG-T ${ }_{\text {abs }}$ & LG-T ${ }_{\text {str }}$ & LG-T ${ }_{\text {abs }}$-Cascade \\
\hline \multicolumn{6}{|c|}{$+10 \%$ change of flue gas flow rate } \\
\hline Accurate & -0.05 & -0.12 & -0.02 & -0.18 & 0.03 \\
\hline Error $+5 \%$ & -0.01 & -1.60 & 0.59 & -1.54 & 0.60 \\
\hline Error $-5 \%$ & 0.00 & 1.14 & -1.06 & 0.97 & -1.03 \\
\hline \multicolumn{6}{|c|}{$-10 \%$ change of flue gas flow rate } \\
\hline Accurate & 0.04 & 0.16 & 0.00 & 0.23 & -0.03 \\
\hline Error $+5 \%$ & & -1.87 & & -1.64 & 0.91 \\
\hline Error $-5 \%$ & & 1.79 & -1.06 & 1.73 & -1.07 \\
\hline \multicolumn{6}{|c|}{$+10 \%$ change of flue gas concentration } \\
\hline Accurate & -0.04 & -0.12 & -0.01 & -0.17 & 0.03 \\
\hline Error $+5 \%$ & -0.01 & -1.93 & - & -1.85 & 0.67 \\
\hline Error $-5 \%$ & 0.01 & -1.52 & -1.01 & -1.32 & 0.93 \\
\hline \multicolumn{6}{|c|}{$-10 \%$ change of flue gas concentration } \\
\hline Accurate & 0.01 & 0.12 & 0.01 & 0.17 & -0.03 \\
\hline Error $+5 \%$ & 0.00 & -1.01 & 0.87 & 1.22 & -0.97 \\
\hline Error $-5 \%$ & 0.00 & 1.46 & -1.14 & 1.40 & -1.14 \\
\hline \multicolumn{6}{|c|}{$+12.5 \%$ change of flue gas temperature } \\
\hline Accurate & 0.00 & 0.07 & -0.01 & 0.11 & -0.01 \\
\hline Error $+5 \%$ & 0.00 & -1.71 & 0.85 & -1.53 & 0.85 \\
\hline Error $-5 \%$ & 0.00 & -1.74 & 0.76 & -1.63 & 0.78 \\
\hline \multicolumn{6}{|c|}{$-12.5 \%$ change of flue gas temperature } \\
\hline Accurate & 0.00 & -0.05 & 0.01 & -0.08 & 0.01 \\
\hline Error $+5 \%$ & 0.00 & 1.53 & -1.02 & 1.45 & -1.01 \\
\hline Error $-5 \%$ & 0.00 & 1.36 & -1.11 & 1.22 & -1.10 \\
\hline
\end{tabular}

CC: capture capacity, $\mathrm{LG}$ : liquid to gas ratio, $\mathrm{T}_{\text {str }}$ : the temperature of a stage of a stripper, $\mathrm{T}_{\text {abs }}$ : the temperature of a stage of the absorber, Cascade: cascade control structure. 


\section{Conclusions}

For the solvent-based post-combustion carbon capture process, which is an important technology but high energy-consuming technology for the remediation of global warming problem, this paper presents the performance of five optimal-based control schemes proposed in this study. These control schemes take the approach of responding to the disturbance or set-point changes by immediately setting optimal values to the set-points of the quality controllers. Although the feedforward control to inform the disturbance change and the on-line optimization are not taken into account by this study, they can be contained in the control system. This study is limited to the stand-alone PCC process not being integrated with a model of the power plant, and that disturbances are considered for flue gas flow close to base load operation conditions or flue gas flow rate close to the full capacity of the absorber column.

Compared to a typical control scheme (CC- $\left.\mathrm{T}_{\text {str }}\right)$, the optimal-based control schemes, with optimal $\mathrm{L} / \mathrm{G}$ (liquid to gas ratio in the absorber) as one of the controlled variable in common, provide faster responses to the disturbance changes from the flue gas conditions and the set-point change of the $\mathrm{CO}_{2}$ capture efficiency. Within the optimal-based control schemes, $\mathrm{LG}-\mathrm{T}_{\text {str }}$ and $\mathrm{LG}-\mathrm{T}_{\mathrm{abs}}-$-Cascade are the best schemes based on the IAEs of capture efficiency and reboiler heat duty.

Supplementary Materials: The following are available online at http://www.mdpi.com/2227-9717/7/6/366/s1, Figure S1: Dynamic responses for disturbance changes of flue gas conditions, Figure S2: Dynamic responses for set-point changes of $\mathrm{CO}_{2}$ capture efficiency.

Author Contributions: H.C., C.D.H., and Y.-H.C. developed the model and control concept. M.-T.S. and Y.-H.C. established the programs and data analysis. All authors contributed to the results, discussion, and conclusions. H.C. and Y.-H.C. prepared the manuscript.

Funding: This research was funded by the Ministry of Science and Technology of Taiwan, grant number MOST 107-2221-E-032-040.

Conflicts of Interest: The authors declare no conflict of interest.

\section{Nomenclature}

$\%$ percent $\mathrm{CO}_{2}$ capture efficiency

$\mathrm{D}$ decision variables

F flow rate $(\mathrm{kmol} / \mathrm{h})$

G gas flow rate $(\mathrm{kmol} / \mathrm{h})$

IAE integral of absolute error

$\mathrm{L} \quad$ liquid flow rate $(\mathrm{kmol} / \mathrm{h})$

LL lean loading $\left(\mathrm{kmol} \mathrm{CO}_{2} / \mathrm{kmol} \mathrm{MEA}\right)$

PCC post-combustion carbon capture

Q heat duty (GJ/hr)

$\overline{\mathrm{Q}} \quad$ specific heat duty $\left(\mathrm{GJ} / \mathrm{kmol} \mathrm{CO} \mathrm{CO}_{2}\right)$

$\mathrm{S}$ process equipment size variables

$\mathrm{T}$ temperature $\left({ }^{\circ} \mathrm{C}\right)$

X process state variables

\section{Subscripts}

$\begin{array}{ll}\text { abs } & \text { absorber } \\ \text { ln } & \text { lean solvent } \\ \text { mu } & \text { makeup } \\ \text { MEA } & \text { monoethanolamine } \\ \text { reb } & \text { reboiler } \\ \text { rich } & \text { rich solvent } \\ \text { str } & \text { stripper }\end{array}$




\section{References}

1. The Global Status of CCS: 2018. Available online: https://www.globalccsinstitute.com/resources/globalstatus-report/ (accessed on 22 December 2018).

2. Bui, M.; Gunawan, I.; Verheyen, V.; Feron, P.; Meuleman, E.; Adeloju, S. Dynamic modelling and optimization of flexible operation in post-combustion $\mathrm{CO}_{2}$ capture plants: A review. Comput. Chem. Eng. 2014, 61, 245-265. [CrossRef]

3. Lawal, A.; Wang, M.; Stephenson, P.; Koumpouras, G.; Yeung, H. Dynamic modelling and analysis of post-combustion $\mathrm{CO}_{2}$ chemical absorption process for coal-fired power plants. Fuel 2010, 89, 2791-2801. [CrossRef]

4. Panahi, M.; Skogestad, S. Economically efficient operation of $\mathrm{CO}_{2}$ capturing process Part II: Design of control layer. Chem. Eng. Process. 2012, 52, 112-124. [CrossRef]

5. Moullec, Y.L.; Kanniche, M. Screening of flowsheet modifications for an efficient monoethanolamine (MEA) based post-combustion $\mathrm{CO}_{2}$ capture. Int. J. Greenh. Gas Control 2011, 5, 727-740. [CrossRef]

6. Moullec, Y.L.; Neveux, T.; Al Azki, A.; Chikukwa, A.; Hoff, K.A. Process modifications for solvent-based post combustion $\mathrm{CO}_{2}$ capture. Energy Procedia 2014, 63, 1470-1477. [CrossRef]

7. Abu-Zahra, M.R.M.; Schneiders, L.H.J.; Niederer, J.P.M.; Feron, P.H.M.; Versteeg, G.F. $\mathrm{CO}_{2}$ capture from power plants: Part I. A parametric study of the technical performance based on monoethanolamine. Int. J. Greenh. Gas Control 2007, 1, 37-46. [CrossRef]

8. Abu-Zahra, M.R.M.; Niederer, J.P.M.; Feron, P.H.M.; Versteeg, G.F. $\mathrm{CO}_{2}$ capture from power plants: Part II. A parametric study of the economical performance based on mono-ethanolamine. Int. J. Greenh. Gas Control 2007, 1, 135-142. [CrossRef]

9. Ziaii, S.; Rochelle, G.T.; Edgar, T.F. Dynamic modeling to minimize energy use for $\mathrm{CO}_{2}$ capture in power plants by aqueous monoethanolamine. Ind. Eng. Chem. Res. 2009, 48, 6105-6111. [CrossRef]

10. Wellner, K.; Marx-Schubach, T.; Schmitz, G. Dynamic behavior of coal-fired power plants with postcombustion $\mathrm{CO}_{2}$ capture. Ind. Eng. Chem. Res. 2016, 55, 12038-12045. [CrossRef]

11. Montañés, R.M.; GarĐarsdóttir, S.Ó.; Normann, F.; Johnsson, F.; Nord, L.O. Demonstrating load-change transient performance of a commercial-scale natural gas combined cycle power plant with post-combustion $\mathrm{CO}_{2}$ capture. Int. J. Greenh. Gas Control 2017, 63, 158-174. [CrossRef]

12. Montañés, R.M.; Flø, N.E.; Nord, L.O. Dynamic process model validation and control of the amine plant at $\mathrm{CO}_{2}$ technology centre mongstad. Energies 2017, 10, 1527. [CrossRef]

13. Garđarsdóttir, S.Ó.; Montañés, R.M.; Normann, F.; Nord, L.O.; Johnsson, F. Effects of $\mathrm{CO}_{2}$-absorption control strategies on the dynamic performance of a supercritical pulverized-coal-fired power plant. Ind. Eng. Chem. Res. 2017, 56, 4415-4430. [CrossRef]

14. Martinez Castilla, G.; Biermann, M.; Montañés, R.M.; Normann, F.; Johnsson, F. Integrating carbon capture into an industrial combined-heat-and-power plant: Performance with hourly and seasonal load changes. Int. J. Greenh. Gas Control 2019, 82, 192-203. [CrossRef]

15. Sharifzadeh, M.; Shah, N. MEA-based $\mathrm{CO}_{2}$ capture integrated with natural gas combined cycle or pulverized coal power plants: Operability and controllability through integrated design and control. J. Clean. Prod. 2019, 207, 271-283. [CrossRef]

16. Sharifzadeh, M.; Shah, N. Carbon capture from natural gas combined cycle power plants: Solvent performance comparison at an industrial scale. AIChE 2016, 62, 166-179. [CrossRef]

17. Panahi, M.; Skogestad, S. Economically efficient operation of $\mathrm{CO}_{2}$ capturing process Part I: Self-optimizing procedure for selecting the best controlled variables. Chem. Eng. Process. 2011, 50, 247-253. [CrossRef]

18. Nittaya, T.; Douglas, P.L.; Croiset, E.; Ricardez-Sandoval, L.A. Dynamic modelling and control of MEA absorption processes for $\mathrm{CO}_{2}$ capture from power plants. Fuel 2014, 116, 672-691. [CrossRef]

19. Montañés, R.M.; Flø, N.E.; Nord, L.O. Experimental results of transient testing at the amine plant at Technology Centre Mongstad: Open-loop responses and performance of decentralized control structures for load changes. Int. J. Greenh. Gas Control 2018, 73, 42-59. [CrossRef]

20. Gjernes, E.; Pedersen, S.; Cents, T.; Watson, G.; Fostås, B.F.; Shah, M.I.; Hamborg, E.S. Results from 30 wt $\%$ MEA performance testing at the $\mathrm{CO}_{2}$ technology centre Mongstad. Energy Procedia 2017, 114, 1146-1157. [CrossRef] 
21. Zhang, Y.; Chen, C.-C. Modeling $\mathrm{CO}_{2}$ absorption and desorption by aqueous monoethanolamine solution with Aspen rate-based model. Energy Procedia 2013, 37, 1584-1596. [CrossRef]

22. Aspen Technology, Inc. Aspen Plus ${ }^{\circledR}$ V10; Aspen Technology, Inc.: Bedford, MA, USA, 2018.

23. Harun, N.; Nittaya, T.; Douglas, P.L.; Croiset, E.; Ricardez-Sandoval, L.A. Dynamic simulation of MEA absorption process for $\mathrm{CO}_{2}$ capture from power plants. Int. J. Greenh. Gas Control 2012, 10, 95-309. [CrossRef]

24. Walters, M.S.; Edgar, T.F.; Rochelle, G.T. Dynamic modeling and control of an intercooled absorber for post-combustion $\mathrm{CO}_{2}$ capture. Chem. Eng. Process. 2016, 107, 1-10. [CrossRef]

25. Flø, N.E.; Knuutila, H.; Kvamsdal, H.M.; Hillestad, M. Dynamic model validation of the post-combustion $\mathrm{CO}_{2}$ absorption process. Int. J. Greenh. Gas Control 2015, 41, 127-141.

26. Zhang, Y.; Chen, H.; Chen, C.; Plaza, J.M.; Dugas, R.; Rochelle, G.T. Rate-based process modeling study of $\mathrm{CO}_{2}$ capture with aqueous monoethanolamine solution. Ind. Eng. Chem. Res. 2009, 48, 9233-9246. [CrossRef]

27. Zhang, Q.; Turton, R.; Bhattacharyya, D. Development of model and model-predictive control of an MEA-based post-combustion $\mathrm{CO}_{2}$ capture process. Ind. Eng. Chem. Res. 2016, 55, 1292-1308. [CrossRef]

28. van de Haar, A.; Trapp, C.; Wellner, K.; De Kler, R.; Schmitz, G.; Colonna, P. Dynamics of post-combustion $\mathrm{CO}_{2}$ capture plants: Modeling, validation, and case study. Ind. Eng. Chem. Res. 2017, 56, 1810-1822. [CrossRef] [PubMed]

29. Chinen, A.S.; Morgan, J.C.; Omell, B.; Bhattacharyya, D.; Miller, D.C. Dynamic data reconciliation and validation of a dynamic model for solvent-based $\mathrm{CO}_{2}$ capture using pilot-plant data. Ind. Eng. Chem. Res. 2019, 58, 1978-1993. [CrossRef]

30. Chen, Y.-H.; Shen, M.-T.; Chang, H. Dynamic modeling and control of the carbon dioxide capture process using monoethanolamine solvent. J. Appl. Sci. Eng. 2019, paper accepted.

31. Aspen Technology, Inc. Jump Start: Aspen Custom Modeler ${ }^{\circledR}$ V8; Aspen Technology, Inc.: Bedford, MA, USA, 2015.

32. Luyben, W.L.; Luyben, M.L. Essentials of Process Control; McGraw-Hill: New York, NY, USA, 1997.

33. Rivera, D.E.; Morari, M.; Skogestad, S. Internal model control 4. PID controller design. Ind. Eng. Chem. Process. Des. Dev. 1986, 25, 252-265. [CrossRef]

34. Shen, M.-T. Dynamic Simulation and Control of Carbon Dioxide Capture System Using Chemical Absorption. Master's Thesis, Department of Chemical and Materials Engineering, Tamkang University, New Taipei City, Taiwan, 2018. 